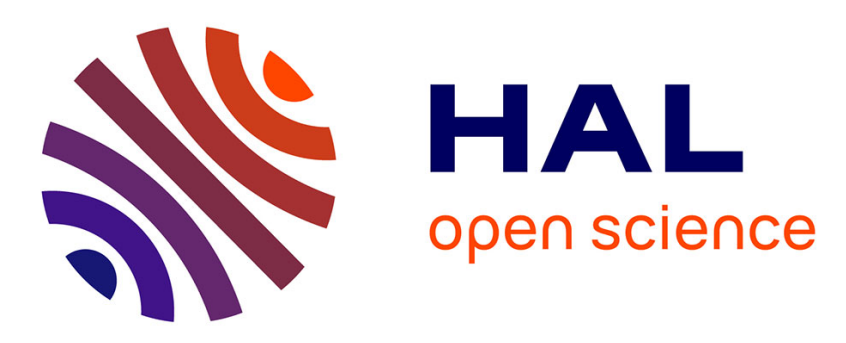

\title{
Simulating Damage and Delamination in Fibre Metal Laminate Joints using a Three-Dimensional Damage Model with Cohesive Elements and Damage Regularisation
}

\author{
R.M. Frizzell, C.T. Mccarthy, M.A. Mccarthy
}

\section{To cite this version:}

R.M. Frizzell, C.T. Mccarthy, M.A. Mccarthy. Simulating Damage and Delamination in Fibre Metal Laminate Joints using a Three-Dimensional Damage Model with Cohesive Elements and Damage Regularisation. Composites Science and Technology, 2011, 10.1016/j.compscitech.2011.04.006 . hal00758605

\section{HAL Id: hal-00758605 https://hal.science/hal-00758605}

Submitted on 29 Nov 2012

HAL is a multi-disciplinary open access archive for the deposit and dissemination of scientific research documents, whether they are published or not. The documents may come from teaching and research institutions in France or abroad, or from public or private research centers.
L'archive ouverte pluridisciplinaire HAL, est destinée au dépôt et à la diffusion de documents scientifiques de niveau recherche, publiés ou non, émanant des établissements d'enseignement et de recherche français ou étrangers, des laboratoires publics ou privés. 


\section{Accepted Manuscript}

Simulating Damage and Delamination in Fibre Metal Laminate Joints using a Three-Dimensional Damage Model with Cohesive Elements and Damage Regularisation

R.M. Frizzell, C.T. McCarthy, M.A. McCarthy

PII: S0266-3538(11)00138-2

DOI: 10.1016/j.compscitech.2011.04.006

Reference: CSTE 4966

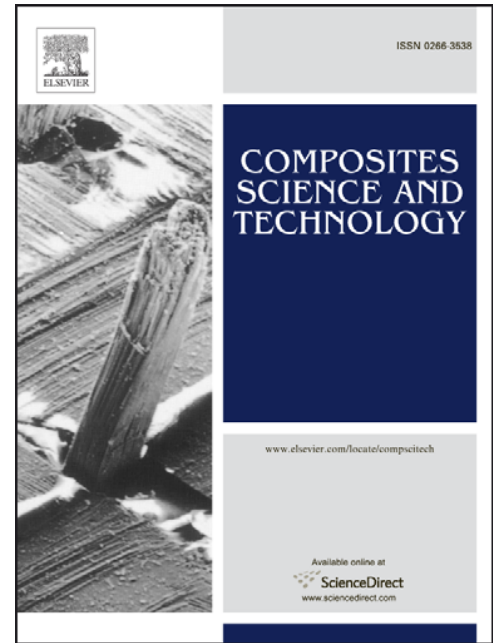

To appear in:

Composites Science and Technology

Received Date:

30 September 2010

Accepted Date:

7 April 2011

Please cite this article as: Frizzell, R.M., McCarthy, C.T., McCarthy, M.A., Simulating Damage and Delamination in Fibre Metal Laminate Joints using a Three-Dimensional Damage Model with Cohesive Elements and Damage Regularisation, Composites Science and Technology (2011), doi: 10.1016/j.compscitech.2011.04.006

This is a PDF file of an unedited manuscript that has been accepted for publication. As a service to our customers we are providing this early version of the manuscript. The manuscript will undergo copyediting, typesetting, and review of the resulting proof before it is published in its final form. Please note that during the production process errors may be discovered which could affect the content, and all legal disclaimers that apply to the journal pertain. 


\title{
Simulating Damage and Delamination in Fibre Metal Laminate Joints using a Three-
}

Dimensional Damage Model with Cohesive Elements and Damage Regularisation

\author{
R.M. Frizzell, C.T. McCarthy*, M.A. McCarthy
}

Composites Research Centre, Materials and Surface Science Institute, Dept. of Mechanical \& Aeronautical Engineering, University of Limerick, Limerick, Ireland

\section{Abstract}

This paper investigates the capability of a three-dimensional finite element model with damaging material behaviour, cohesive elements and damage regularisation to simulate complex damage patterns in fibre metal laminate (FML) joints. The model incorporates a three-dimensional continuum damage mechanics approach for the composite plies, a plasticity model for the aluminium layers, and a delamination model between layers. A nonlocal averaging scheme is implemented to mitigate the mesh sensitivity that occurs with strainsoftening material models. Bearing stress-strain responses and variations in stiffness are calculated, and damage progression is described in detail for all plies and interfaces. Microscopy and stress-strain data from a parallel series of experimental tests are presented, and damage and failure phenomena observed in the tests are compared with the model. Generally, good agreement between model and tests was achieved but certain limitations of the numerical model were observed and are discussed. The combined numerical and experimental information provide a detailed understanding of the failure sequence of FML joints.

Keywords: Joints; A: Hybrid composites, C: Computational mechanics, C: Modelling * conor.mccarthy@ul.ie, (Ph. +353 (0)61 23 4334, Fax +353 (0)61 20 2944)

\subsection{Introduction}

The use of composite materials by commercial aircraft companies in primary structural components is increasing significantly with the advent of composite fuselage sections and composite wings. Traditional aircraft design uses a mechanical testing pyramid approach to characterise the performance of structural components, featuring tests from coupon level at the bottom of the pyramid, up to full-scale aircraft tests at the highest pyramid level. This is a robust approach to aircraft design but leads to costly and time-consuming design phases. 
Numerical analysis tools can be used to reduce the number of tests required, decreasing development costs and lead-time. Experimental testing is, however, essential for the basic material characterisation, validation of numerical models and final certification of aircraft components. The proper combination of experimental and numerical analysis techniques can allow complex structures to be efficiently optimised. For numerical models to make valid contributions to this process they must be shown to correctly represent material and structural behaviour right through the loading process. For the design of complex composite structures, this requires the prediction of damage and delamination initiation and growth in jointed structures.

Fibre Metal Laminates (FMLs) are a family of advanced aerospace materials that are of particular interest to the aerospace industry, consisting of alternating layers of thin metal sheets and fibre-reinforced plastic. FMLs originated at Fokker/TU Delft in the Netherlands during the late 1970s and since then have undergone extensive development [1-3]. FMLs boast a number of favourable characteristics, such as excellent fatigue performance, high residual and blunt notch strengths, good impact resistance, and low density [1].

The focus of this paper is on the in-service behaviour of FMLs, specifically in jointed configurations. Such an investigation is warranted since bolted and riveted joints represent potential weak points in a structure, and their efficient design is therefore critical to the loadcarrying capability and weight of the structure. The performance of such joints is influenced by a number of factors (such as material type, layup and geometry), which makes their analysis and design extremely challenging.

Finite element studies of FMLs have been conducted on both notched $[4,5]$ and unnotched FMLs [6], along with pin and bolt bearing configurations [7] and riveted joints [8]. Both damaging and linear elastic material properties have been used for modelling the composite layers of FMLs. The pin-bearing investigation of van Rooijen [7] concentrated mainly on the delamination behaviour of FMLs and incorporated only a basic description of in-plane damage in the composite layers. Lapczyk \& Hurtado [5] described a model, which used Hashin's [9] failure criteria to account for a number of in-plane damage modes in the composite layer. Hardening plasticity was modelled in the aluminium and delamination between the various layers was captured by interface elements. However, very limited validation was performed.

The work in this paper examines the capability of a finite element model with a threedimensional damage model, cohesive elements and damage regularisation to simulate 
complex three-dimensional damage patterns in fibre metal laminate joints. Both initiation and progression of damage is modelled. Detailed comparisons are made with our own experimental observations [10] enabling a thorough evaluation of the model.

\subsection{Overview of Experimental Programme}

The material chosen for this study was GLARE ${ }^{\circledR} 3$ 3/2 0.4 L glass-fibre based FML, which was purchased from a commercial materials supplier. The lay-up was [AL/0/90/AL/90/0/AL] (where AL represents an aluminium layer and 0 and 90 refer to the orientation of the composite layers with respect to the loading direction). The aluminium layers were $0.4 \mathrm{~mm}$ thick and each composite layer was approximately $0.125 \mathrm{~mm}$ thick, giving a nominal laminate thickness of $1.7 \mathrm{~mm}$.

The specimen geometry and loading are shown in Figure 1(a), while a schematic of the experimental set-up is shown in Figure 1(b). The pin-bearing test setup used here is generally considered to represent a worst case scenario for in-service conditions since out-ofplane deformation is unconstrained leading to lower joint strengths. A $6 \mathrm{~mm}$ neat-fit hardened steel pin was inserted into the hole and then loaded under displacement control via a specially designed testing frame. The deflection of the pin was measured using displacement gauges. The specimen dimensions were designed to promote bearing failure, with a width to hole diameter (w/d) ratio of 6, and an edge distance to hole diameter (e/d) ratio of 6. Each specimen had a length of $\mathrm{L}=135 \mathrm{~mm}, 50 \mathrm{~mm}$ of which was held by the machine clamp. Five tests to failure were carried out and showed excellent repeatability. Full bearing stress-bearing strain curves were recorded and a microscopy study was undertaken on specimens loaded to ultimate failure and to percentages of their ultimate failure load. Figure 1(c) shows the bearing plane analysed in the microscopy study. A complete description of the experimental results is contained in [10].

\subsection{Composite Damage Model Description}

A three-dimensional Continuum Damage Mechanics (CDM) meso-scale damage model, similar to that described by Ladevèze \& Le Dantec [11], was implemented in the nonlinear finite element code ABAQUS. The model predicts different modes of composite damage and is formulated by introducing scalar damage variables that degrade the initial material properties. Variations of the Ladevèze meso-model have been implemented successfully by a number of researchers [12-15]. 
The damage model is succinctly described by the damaged strain energy density as:

$$
\begin{gathered}
E_{D}=\frac{1}{2}\left[\left(\frac{\sigma_{11}^{2}}{E_{11}^{0}\left(1-d_{1}\right)}\right)+\left(\frac{\sigma_{22}^{2}}{E_{22}^{0}\left(1-d_{2}\right)}\right)+\left(\frac{\sigma_{33}^{2}}{E_{33}^{0}}\right)-2\left(\frac{\sigma_{11} \sigma_{22} v_{12}}{E_{11}^{0}}\right)-2\left(\frac{\sigma_{11} \sigma_{33} v_{13}}{E_{11}^{0}}\right)\right. \\
\left.-2\left(\frac{\sigma_{22} \sigma_{33} v_{23}}{E_{22}^{0}}\right)+\left(\frac{\tau_{12}^{2}}{G_{12}^{0}\left(1-d_{12}\right)}\right)+\left(\frac{\tau_{13}^{2}}{G_{13}^{0}}\right)+\left(\frac{\tau_{23}^{2}}{G_{23}^{0}}\right)\right]
\end{gathered}
$$

in which subscripts 1,2 and 3 denote the fibre, transverse and thickness directions, $d_{1}, d_{2}$ and $d_{12}$ are the scalar damage variables in the fibre, transverse tension and shear directions, respectively, and $E^{0}, G^{0}$ and $v$ are the ply elastic properties. Note that the fibre direction damage variable, $d_{1}$, and the transverse direction damage variable, $d_{2}$, develop differently depending on whether the loading is tensile or compressive.

\subsection{In-plane tensile response}

Following the general formulation of $\mathrm{CDM}$, thermodynamic forces are introduced that are derived from Eqn. 1 and these govern development of shear and transverse tensile damage. Material healing is prevented by setting the thermodynamic forces, $Y_{2}$ and $Y_{12}$, to their maximum values over any previous time $\tau$ up to the current time $t$ :

$$
\begin{array}{cc}
\underline{Y}_{12}(t)=\max _{\tau \leq t}\left(\left.\frac{\partial E_{D}}{\partial d_{12}}\right|_{\sigma, d_{1}, d_{2}}\right)=\max _{\tau \leq t}\left(\frac{\tau_{12}^{2}}{2 G_{12}^{0}\left(1-d_{12}\right)^{2}}\right) & \text { Eqn. } 2 \\
\underline{Y}_{2}(t)=\max _{\tau \leq t}\left(\left.\frac{\partial E_{D}}{\partial d_{2}}\right|_{\sigma, d_{1}, d_{12}}\right)=\max _{\tau \leq t}\left(\frac{\left\langle\sigma_{22}\right\rangle_{+}^{2}}{2 E_{22}^{0}\left(1-d_{2}\right)^{2}}\right) & \text { Eqn. 3 }
\end{array}
$$

An additional quantity is defined by

$$
\hat{Y}(t)=\sqrt{\underline{Y}_{12}(t)+b \underline{Y}_{2}(t)}
$$

Eqn. 4

where $b$ is a parameter introduced to account for transverse tension/shear coupling. $\underline{Y}(t)$ drives both the shear and transverse tensile damage variables, $d_{12}$ and $d_{2}$, respectively.

O'Higgins [16] describes experimental tests on unnotched $\pm 45^{\circ}$ and $\pm 67.5^{\circ}$ S2FM94 GFRP laminates, carried out in our laboratory to calibrate the damage model. The composite layers of the FML of interest in this paper use the same S2FM94 material system as in [16]. The tests yield the coupling parameter, $b$, and the values of the damage variables, $d_{12}$ and $d_{2}$, as functions of $\underline{Y}(t)$. Graphs of these functions are called the damage master curves and are used as input for the current damage model. Examples of these damage master curves are shown in Figure 2(a) and (b).

The accumulation of permanent strains is accounted for in the Ladevèze damage model [11]. However, this mechanism was not included here for the composite layers as the loading was quasi-static and monotonic. 
Figure 2(c) shows the evolution of the fibre-direction damage variable, $d_{1}$. Below the tensile fibre damage initiation strain, $\varepsilon_{11}^{i}, d_{1}$ is zero. Then damage grows linearly from $\varepsilon_{11}^{i}$ to $\varepsilon_{11}^{u}$, where $\varepsilon_{11}^{u}$ is a threshold strain. Beyond $\varepsilon_{11}^{u}$ damage grows asymptotically towards 1 , which avoids numerical difficulties associated with zero stiffness in the fibre direction.

\subsection{In-plane compressive response}

The compressive and tensile stiffnesses in the fibre direction were assumed to be equal and compressive behaviour was modelled as linear elastic prior to damage initiation. The compressive fibre damage variable, $d_{1 C}$, grew in a similar manner to the tensile fibre direction (Figure 2(c)) and a compressive damage initiation strain, $\varepsilon_{11 C}^{i}$, and threshold strain, $\varepsilon_{11 C}^{u}$, were defined based on compressive strength measurements performed within our laboratory.

The material was assumed to be linear elastic to failure under transverse compression. This follows the assumption of Ladevèze \& Le Dantec [11] that under compressive loading microcracks close and, therefore, progressive damage development does not occur. Ultimate failure in transverse compression was assumed to occur when the Hashin [9] compressive matrix failure criterion was satisfied:

$$
\frac{1}{S_{22}^{C}}\left[\left(\frac{S_{22}^{C}}{2 S_{23}}\right)^{2}-1\right]\left(\sigma_{22}+\sigma_{33}\right)+\frac{\left(\sigma_{22}+\sigma_{33}\right)^{2}}{4 S_{23}^{2}}+\frac{\left(\sigma_{23}^{2}-\sigma_{22} \sigma_{33}\right)}{S_{23}^{2}}+\frac{\left(\sigma_{12}^{2}+\sigma_{13}^{2}\right)}{S_{12}^{2}} \geq 1
$$

Eqn. 5

where $\sigma_{i j}$ are components of the stress tensor, $S_{i j}$ are the material strengths in directions, $i$ and $j$, and superscript $C$ refers to compression. Figure 2(d) shows the linear evolution of the compressive matrix damage variable, $d_{2 C}$, with the effective thermodynamic force, $\underline{\hat{Y}}_{C}$, which is defined as:

$$
\underline{\hat{Y}}_{C}(t)=\sqrt{\underline{Y}_{12}(t)+b \underline{Y}_{2 C}(t)}
$$

Eqn. 6

where, $\underline{Y}_{12}(t)$ is defined in Eqn. 2, while $\underline{Y}_{2 C}(t)$ is determined from Eqn. 3 using $\left\langle\sigma_{22}\right\rangle_{-}^{2}$ in place of $\left\langle\sigma_{22}\right\rangle_{+}^{2}$. In Figure 2(d), $\underline{\hat{Y}}_{C}^{i}$ is the value of Eqn. 6 when Eqn. 5 is first satisfied and $\underline{\hat{Y}}_{C}^{u}$ was set to 1.2 times $\underline{\hat{Y}}_{C}^{i}$, to allow some energy dissipation following compressive matrix failure and to help stabilise the numerical procedure, as it avoids immediate loss of material stiffness. $\underline{Y}_{C}^{i}$ was chosen as it varies with transverse and shear strain, which both contribute to the development of compressive matrix damage.

\subsection{Delamination modelling}

Delamination of the FML layers was a dominant failure mechanism in the experiments of [10] and so cohesive elements, which are part of the ABAQUS software, were used in 
areas of the model where delamination was expected (such as near the pin-hole). These elements are represented in a similar manner to regular continuum elements and the relative motion between the upper and lower element faces defines the opening and closing of the interface. The traction across the interface in the normal direction (zz) and two shear directions (xz, yz) was controlled by a bi-linear traction-separation law. This law ensured a linear elastic response up to delamination initiation, followed by a linear softening phase. Delamination initiation is controlled by a quadratic stress-based criterion, which accounts for the interaction of tractions in the normal and shear directions. Mixed-mode behaviour is also accounted for during damage evolution in the softening phase using the Benzeggagh-Kenane (BK) criterion (with $\eta=1$ ) [17]. Following delamination initiation, unloading occurs at reduced stiffness directly towards the origin and the elements maintain resistance to compressive normal loads, thus preventing interpenetration should the layers re-contact each other. A complete description of the cohesive element formulation is given in Ref [17]. The material properties used are shown in Table 1 and are discussed in Section 5.0.

\subsection{Nonlocal Regularisation Scheme}

A fundamental problem with including strain-softening material models, such as the damage model discussed above, in standard continuum models is that they suffer from inherent mesh sensitivity. The root cause is a change of character of the governing differential equations [18], which results in them becoming ill-posed. This problem manifests itself in damage zones that tend to localise in a band that is one element wide and the width of this zone diminishes as the mesh is refined. This leads to numerical simulations where the solution is dependent on the analyst's choice of mesh, and convergence of results with successive mesh refinements is not achieved.

A number of regularisation methods have been proposed to mitigate the effects of mesh-sensitivity. Perhaps the most widely used is the Crack Band Model proposed by Bazant \& Oh [19]. This approach is implemented in a relatively straightforward manner by adjusting the damage evolution portion of the material's constitutive law, ensuring the correct energy is dissipated regardless of the element size. Bazant \& Jirasek [20] describe how the Crack Band Model captures the global load-displacement curve correctly, but the predicted width of the fracture process zone (or crack band) depends on the size of the elements and tends to zero as the mesh is refined. The Crack Band Model also suffers from a mesh directionality bias, where the damage tends to follow mesh lines and therefore the direction of crack band 
propagation will change as the mesh is refined [21]. The crack band width and the mesh orientation bias are problematic features of the Crack Band Model, especially evident when experimental and numerical damage progression maps are compared.

Bazant and co-workers $[20,22]$ have shown the nonlocal approach to be an effective means of mitigating mesh-sensitivity issues. Weighted averaging is used to ensure the constitutive response of any point is dependent on the behaviour of the surrounding material. This approach demonstrates excellent convergence behaviour for successively refined meshes when using strain-softening material models and it also alleviates mesh orientation bias [20].

The nonlocal approach is implemented by determining the spatial average of a local field $f(\phi)$ over a certain domain, $\Omega$, according to

$$
\bar{f}(\phi)=\frac{1}{\Psi(\phi)} \int_{\Omega} \psi(\phi, \xi) f(\xi) d \Omega, \quad \Psi(\phi)=\int_{\Omega} \psi(\phi, \xi) d \Omega
$$

where $\psi(\phi, \xi)$ is the chosen weighting function between the receiver point, $\phi$, and the source point, $\xi$. A key aspect of the nonlocal approach is the size of the characteristic length, $l^{*}$, which defines the region of influence around a receiver point. Any points lying outside this region are not used in the averaging calculations. The nonlocal method is particularly appealing for CDM models, since damage growth can be controlled by an average of nonlocal variables, such as the thermodynamic force (Eqn. 4), without the need to change the basic formulation of the material model.

With the nonlocal method, each integration point must query the surrounding integration points during the evaluation of material behaviour. This poses significant problems in ABAQUS because the UMAT subroutine, used to define the material behaviour, is called for a single integration point at a time and any information about surrounding points is not directly available. A solution is to store state variables in each increment and then to read these values in the following increment. This leads to an explicit evaluation of the material state and it is, therefore, essential to keep the size of the time step small to minimise errors in the approximation.

Some methods have previously been discussed to determine the value of the characteristic length, $l^{*}$, (see for example Ref [23]). In the current work an inverse modelling of experimental tests was performed. The experimental results were from an open hole tension (OHT) specimen with a cross-ply layup [16]. For the material system of interest (S2FM94), $l^{*}$ was found to be $1.26 \mathrm{~mm}$. To implement the model the components of the strain 
tensor were averaged when strain-softening was detected. The averaged strain was then used as input to the composite damage model.

Compared to a standard finite element simulation, the nonlocal approach requires additional computational resources. The mesh topology must be analysed to determine which areas interact and the resulting mesh connectivity data must be stored. The averaging calculations also add to the standard run-time. These problems are compounded as the mesh size increases, potentially leading to computationally expensive analyses.

An OHT specimen was used to demonstrate the performance of the nonlocal approach. Only a small area of the specimen was modelled, as shown in Figure 3(a), and anisotropic material properties were applied. Four $0^{\circ}$ layers were modelled and only damage in the loading direction was considered. A simple strain-based failure criterion, as described in Section 3.1, was applied. Four analyses were conducted with variable mesh density, as indicated by the number of degrees of freedom (DOF) in Figure 3. The unregulated damage model response, shown in Figure 3(b), displays a significant decrease in predicted peak load for successively refined meshes. In contrast, the nonlocal model, shown in Figure 3(c), exhibits consistent peak load predictions, despite the large variation of mesh density.

\subsection{Pin-Bearing Model Description}

The boundary and loading conditions are shown in Figure 4(a). Friction was modelled between the rigid pin and the laminate using a penalty approach and a small coefficient of friction of 0.1 was chosen.

Each FML layer was modelled separately and tied constraints held the layers together. Each layer was discretized with one element in the thickness direction, except the outer aluminium layer, which used three elements through the thickness to improve the out-of-plane bending prediction. Figure 4(b) shows the bearing specimen mesh, with a close-up of the mesh near the pin-hole. Solid eight-node linear elements with incompatible modes were used in the vicinity of the pin-hole, due to their favourable performance in bending. To improve analysis runtimes, reduced integration elements were used away from the pin-hole.

Cohesive layers were introduced to allow the development of delamination next to the pin-hole. The dimensions of the cohesive layers are shown in Figure 4(c). Table 1 shows the interface material properties, which were taken from $[24,25] . K_{P}$ is the initial interface stiffness, $G_{z C}$ and $G_{s h C}$ are the interface fracture toughness values and $S_{z z}$ and $S_{s h}$ are the interface strengths in the normal and shear directions, respectively. 
An elastic-plastic model with a Von Mises stress yield criterion and isotropic hardening was used for the aluminium layers. The aluminium material properties were $\mathrm{E}=$ $73.8 \mathrm{MPa}, v=0.33$ and the plastic hardening data are as given by Preusch et al. [8].

The basic material properties for the S2FM94 composite layers, as measured experimentally in our laboratory by O'Higgins [16], are shown in Table 2. The material properties specific to the damage model used herein are shown in Table 3. The development of shear and transverse tensile damage, $d_{12}$ and $d_{2}$, was described by the experimentally measured damage master curves shown in Figure 2(a) and (b), respectively [16].

The in-plane composite damage model with the nonlocal regularisation scheme was implemented in ABAQUS via the user material subroutine UMAT and was first tested on unnotched S2FM94 laminates. The response of the model is shown in Figure 5 for laminates with various layups. Experimental results were compared with the numerical predictions and a close correlation was found, giving confidence in the model and material parameters.

\subsection{Bearing Stress-Bearing Strain Response}

Figure 6 shows the numerical and experimental bearing stress-bearing strain results. The bearing stress is defined as $\sigma_{B r}=P / d h$, where $P$ is the applied load, $d$ is the hole diameter and $h$ is the specimen thickness. The bearing strain is $\varepsilon_{B r}=\delta / d$, where $\delta$ is the pindisplacement. The variation in joint stiffness, also shown in these figures, has been used by McCarthy et al. [26] as an indicator of damage progression in composites. The numerical and experimental results were in good agreement and both exhibited similar trends in the bearing stress and stiffness responses. The model began to lose its initial stiffness at approximately the same level of bearing strain as measured experimentally. However, the initial stiffness was over predicted and the rate at which the stiffness was lost was higher for the numerical model.

The numerical results demonstrate a severe change in stiffness at approximately $2.4 \%$ bearing strain. This was caused by the initiation and growth of compressive fibre damage, which is verified with damage progression maps in the next section. The residual bearing specimen stiffness is very low but generally remains positive, allowing the bearing stress to increase following compressive fibre damage initiation.

\subsection{Damage Progression}

Figures 7 to 11 present the damage progression plots for varying levels of bearing strain. The bearing stress-bearing strain curves and the bearing stiffness-bearing strain curves 
are also included in each figure, and the point in the loading history to which the damage maps correspond is marked, to provide insight into the effect damage has on the overall specimen response. A scanning electron micrograph is shown for each case where one was available.

The intensity of damage in the $0^{\circ}$ and $90^{\circ}$ composite layers is described according to the damage legend and grows from 0 (undamaged) to 1 (complete failure). The level of delamination in the interface layers is also described by the same damage legend. The intensity of plastic strain in the aluminium layers is similarly described by a separate legend; note the maximum value of plastic strain used in the legends is the same for all figures to allow direct comparison. The maximum value of plastic strain is also given in each figure.

At $1.2 \%$ bearing strain (Figure 7 ), the specimen has lost approximately $20 \%$ of its initial stiffness. The main cause of this is the accumulation of plasticity within the aluminium layers (note: though the contours do not show plastic strain due to the maximum value chosen for the legend, the maximum plastic strain in Figure 7 is $0.37 \%$ ). Shear and transverse tensile damage ( $d_{12}$ and $d_{2}$ respectively) in the $0^{\circ}$ and $90^{\circ}$ composite layers have also contributed to this initial stiffness loss, though considering the low level of damage and the thin nature of the composite layers, this contribution is likely to be low

By $2.3 \%$ bearing strain (Figure 8 ) the specimen has lost over $50 \%$ of its initial stiffness. The corresponding load level is approximately $80 \%$ of the experimentally determined failure load. In agreement with the experimental observations (see SEM insert in Figure 8), the numerical model predicts small amounts of delamination at the bearing plane. The model also predicts significant levels of compressive matrix damage $\left(d_{2 C}\right)$ at the bearing plane in the $90^{\circ}$ layer, which is expected considering the local transverse direction (i.e. the " 2 " direction) coincides with the loading direction and so the $90^{\circ}$ ply is heavily loaded in transverse compression. This is consistent with the SEM micrograph in Figure 8, which shows evidence that the $90^{\circ}$ ply has undergone significant levels of compression at the bearing plane.

At $3 \%$ bearing strain (Figure 9), approximately $90 \%$ of experimental failure load, some cracking of the fibres in the $0^{\circ}$ composite layer is evident in the micrograph. Similar damage is predicted by the model at this load level $\left(d_{1 c}\right)$, however, the effect this has on the model response is much more pronounced than that observed experimentally. This is seen from the sharp drop in bearing stiffness between 2.3\% (Figure 8) and 3\% (Figure 9) bearing strain. Figures 8 and 9 show that most other damage mechanisms also intensify after 
compressive fibre damage $\left(d_{1 C}\right)$ is predicted, which contributes to the severe loss in specimen stiffness.

From 3\% (Figure 9) to 4\% (Figure 10) bearing strain (95\% failure load), it is interesting to note that there is little increase in in-plane composite damage, but there is a noticeable increase in delamination area and aluminium plastic strain. Numerically, once the initial fibre breakages have occurred in the $0^{\circ}$ layer (Figure 9), the elements closest to the hole soften, and the composite actually unloads, which stops the development of the in-plane composite damage until the stress builds up again at higher strains and causes further in-plane composite damage. Experimentally, once the initial fibres crack, the composite takes little of the load, until compaction of the fragments causes the unbroken portions of the fibres to be loaded again. The increased delamination is also clear from the SEM images in Figures 9 and 10.

Between $4 \%$ (Figure 10) and 8\% (Figure 11) bearing strain there is only a slight increase in bearing stress with increasing bearing strain. The damage maps show that the amount of damage also increases over this region but does not lead to a clear-cut ultimate failure load being predicted. There are two major fluctuations in the bearing stress-strain curve beyond $4 \%$ bearing strain, which are caused by compressive fibre damage $\left(d_{1 C}\right)$ initiating in additional elements near the bearing plane. The bearing stress increases following each of these fluctuations making it difficult to determine an ultimate failure load. However, the specimen stiffness is approximately zero after $4.5 \%$ bearing strain and so it is reasonable to consider the specimen failed after this point.

It is interesting to note how the predicted plasticity in the aluminium layers remains localised next to the hole all through the loading process, while the damage in the composite layers propagates quite far from the hole edge.

Beyond approximately $6 \%$ bearing strain, the accuracy of the analysis broke down.

This was due to the heavily damaged elements ahead of the pin offering little resistance to the pin motion. The predicted deformation of these elements became large and inaccuracies resulted. At larger bearing strains, the pin was predicted to pass through certain elements of the mesh, causing an inaccurate description of load transfer between the pin and the laminate.

\subsection{Concluding Remarks}

This paper investigates the capability of a continuum damage mechanics model to analyse the complex damage development in jointed FMLs. The model incorporates a three- 
dimensional continuum damage mechanics approach for the composite plies and a plasticity model for the aluminium layers, along with a delamination model between layers. The importance of mitigating the effects of mesh sensitivity, associated with strain-softening material models, was highlighted. A nonlocal approach was implemented to enhance the damage model, and was shown to be very effective at alleviating the mesh dependency. This approach is, however, challenging to implement using commercial codes, and increases the memory requirements and run-times over standard finite element analyses.

The performance of the model was assessed by comparison to previously reported experimental results [10]. Very good agreement was achieved between numerical and experimental bearing stress-strain and bearing stiffness-strain responses, especially considering the complex nature of the model being analysed. Correlation with microscopy indicated reasonably accurate prediction of the sequence of damage initiation and growth, and the model provides additional insight into the damage mechanisms active at each stage of loading and the effect of these mechanisms on the joint behaviour.

Some discrepancies between model and experiment are apparent. For example, the initial stiffness is over estimated. Possible causes are inaccuracies in the clamping boundary conditions, or in the elastic (particularly compressive) material parameters. The numerical model was also unable to predict a clearly defined ultimate load, which was a feature of the experimental response. However, as the model stiffness was approximately zero at $4.5 \%$ bearing strain, the joint could be considered failed at this point.

According to the model, the initial loss of joint stiffness is due to shear and transverse tensile damage in the composite layers and low levels of plasticity in the aluminium layers. With increasing pin-displacement, these damage mechanisms intensify and compressive matrix damage initiates next to the pin in the $90^{\circ}$ prepreg layers. Delamination occurs between the layers immediately adjacent to the pin and remains localised in a small region surrounding the pin-hole (of the order of $1 \mathrm{~mm}$ from the hole edge) throughout the analysis. The joint is severely affected when compressive fibre damage initiates, resulting in very low residual stiffness and a long plateau region in the bearing stress-strain curve.

The modelling strategy is currently being improved by employing a more sophisticated failure criterion for compressive matrix damage, such as that used in the LaRC04 criteria [27]. The relatively straightforward model for predicting transverse tensile and shear damage will also be enhanced by accounting for the effects of plasticity in the matrix material, as described in the work of Ladevèze \& Le Dantec [11]. 


\section{Acknowledgements}

The authors would like to thank the Irish Research Council for Science, Engineering and Technology (IRCSET) for funding this work. Computational work was carried out using the MSSI AMPS cluster, enabled under the framework of the INSPIRE programme, funded by the Irish Government's Programme for Research in Third Level Institutions, Cycle 4, National Development Plan 2007-2013.

\section{References}

[1] Vlot A, Vogelesang LB, de Vries TJ. Towards Application of Fibre Metal Laminates in Large Aircraft. Aircraft Engineering and Aerospace Technology. 1999;71(6):558 - 570.

[2] Gunnink JW, Vlot A, de Vries TJ, van der Hoeven W. GLARE Technology Development 1997 - 2000. Applied Composite Materials. 2002;9:201 - 219.

[3] Vogelesang LB, Vlot A. Development of Fibre Metal Laminates for Advanced Aerospace Structures. Journal of Materials Processing Technology. 2000;103:1 - 5.

[4] de Vries TJ. Blunt and Sharp Notch Behaviour of Glare Laminates PhD. Delft University of Technology, Faculty of Aerospace Engineering, 2001.

[5] Lapczyk I, Hurtado JA. Progressive Damage Modeling in Fiber-Reinforced Materials. Composites Part A. 2007;38:2333 - 2341.

[6] Hashagen F, Schellekens JCJ, de Borst R, Parisch H. Finite Element Procedure for Modelling Fibre Metal Laminates. Composite Structures. 1995;32:255 - 264.

[7] van Rooijen RGJ. Bearing Strength Characteristics of Standard and Steel Reinforced GLARE PhD. Delft University of Technology, Faculty of Aerospace Engineering, 2006.

[8] Preusch K, Linde P, Pleitner J, de Boer H, Carmone C. Modelling of Fibre Metal Laminate Shells Applied to the Inter Rivet Buckling Phenomenon. European Congress on Computational Methods in Applied Sciences and Engineering (ECCOMAS), Jyväskylä2004.

[9] Hashin Z. Failure Criteria for Unidirectional Fibre Composites. Journal of Applied Mechanics. 1980;47(June):329 - 334.

[10] Frizzell RM, McCarthy CT, McCarthy MA. An Experimental Investigation into the Progression of Damage in Pin-Loaded Fibre Metal Laminates. Composites Part B: Engineering. 2008;39(6):907 - 925.

[11] Ladeveze P, Le Dantec E. Damage Modelling of the Elementary Ply for Laminated Composites. Composites Science and Technology. 1992;43:257 - 267.

[12] Phillips EA, Herakovich CT, Graham LL. Damage Development in Composites with Large Stress Gradients. Composites Science and Technology. 2001;61:2169 - 2182. 
[13] McCarthy MA, Xiao JR, Petrinic N, Kamoulakos A, Melito V. Modelling of Bird Strike on an Aircraft Wing Leading Edge Made from Fibre Metal Laminates - Part 1: Material Modelling. Applied Composite Materials. 2004;11:295 - 315.

[14] Bordreuil C, Hochard C. Finite Element Computation of Woven Ply Laminated Composite Structures up to Rupture. Applied Composite Materials. 2004;11:127 - 143.

[15] Allix O, Blanchard L. Mesomodeling of Delamination: Towards Industrial Applications. Composites Science and Technology. 2006;66:731 - 744.

[16] O'Higgins RM. An Experimental and Numerical Study of Damage Initiation and Growth in High Strength Glass and Carbon Fibre-Reinforced Composite Materials PhD. University of Limerick, College of Engineering, 2007.

[17] ABAQUS-Inc. ABAQUS Analysis User's Manual, Version 6.6. Pawtucket, RI, USA: Hibbett, Karlsson and Sorensen Inc.; 2006.

[18] de Borst R, Sluys LS, Muhlhaus HB, Pamin J. Fundamental Issues in Finite Element Analysis of Localization of Deformation. Engineering Computations. 1993;10:99 - 120.

[19] Bazant ZP, Oh BH. Crack Band Theory for Fracture of Concrete. Materials and Structures. 1983;16(93):155 - 177.

[20] Bazant ZP, Jirasek M. Nonlocal Integral Formulations of Plasticity and Damage: Survey of Progress. Journal of Engineering Mechanics. 2002;128(11):1119 - 1149.

[21] Donadon MV, de Almeida SFM, Arbelo MA, de Faria AR. A Three-Dimensional Ply Failure Model for Composite Structures. International Journal of Aerospace Engineering. 2009;Volume 2009(Article ID 486063):1 - 22.

[22] Bazant ZP, Lin FB. Nonlocal Smeared Cracking Model for Concrete Fracture. Journal of Structural Engineering. 1988;114(11):2493 - 2510.

[23] Geers MGD, de Borst R, Brekelmans WAM, Peerlings RHJ. Validation and Internal Length Scale Determination for a Gradient Damage Model: Application to Short Glass-Fibre-Reinforced Polypropylene. International Journal of Solids and Structures. 1999;36:2557 - 2583.

[24] Hashagen F, de Borst R, de Vries TJ. Delamination Behavior of Spliced Fiber Metal Laminates. Part 2. Numerical Investigation. Composite Structures. 1999;46:147-162.

[25] Remmers JJC, de Borst R. Delamination Buckling of Fibre-Metal Laminates. Composites Science and Technology. 2001;61:2207 - 2213.

[26] McCarthy MA, Lawlor VP, Stanley WF, McCarthy CT. Bolt-Hole Clearance Effects and Strength Criteria in Single-Bolt, Single-Lap, Composite Bolted Joints. Composites Science and Technology. 2002;62:1415 - 1431.

[27] Maimi P, Camanho PP, Mayugo JA, Davila CG. A Continuum Damage Model for Composite Laminates: Part I - Constitutive Model. Mechanics of Materials. 2007;39:897 - 908. 
Figure 1: (a) Pin-bearing test configuration and joint parameters (b) Schematic showing salient features of the experimental set-up (c) Definition of planes of interest and circumferential coordinate, $\theta$

Figure 2: (a) Shear damage master curve (b) transverse tensile damage master curve (c) evolution of fibre direction tensile damage variable (d) evolution of the compressive matrix damage variable

Figure 3: (a) Open Hole Tension (OHT) specimen showing area of interest in the mesh refinement study (b) the unregulated stress-strain response (c) nonlocal model response

Figure 4: (a) Boundary and loading conditions of the bearing specimen (note: clamped region was not modelled), (b) plan view of applied mesh and (c) overview of cohesive layer

Figure 5: Predicted versus experimental response of unnotched laminates (a) $\left[0^{\circ}\right] 4$ (b) $[90] 4$ (c) $\left[ \pm 45^{\circ}\right] \mathrm{s}(\mathrm{d})\left[ \pm 67.5^{\circ}\right] \mathrm{s}$ transverse response (e) $\left[ \pm 67.5^{\circ}\right] \mathrm{s}$ shear response. Experimental results from [16]

Figure 6: Experimental versus numerical bearing stress-strain response, along with the variation of specimen stiffness for the bearing specimen

Figure 7: Damage distribution in the various layers of the bearing specimen at $300 \mathrm{MPa}$ bearing stress and $1.2 \%$ bearing strain

Figure 8: Damage distribution in the various layers of the bearing specimen at $450 \mathrm{MPa}$ bearing stress and $2.3 \%$ bearing strain, with insert showing the bearing plane SEM micrograph of the bearing specimen at a similar load level

Figure 9: Damage distribution in the various layers of the bearing specimen at $490 \mathrm{MPa}$ bearing stress and $3.0 \%$ bearing strain, with insert showing the bearing plane SEM micrograph at similar load level

Figure 10: Damage distribution in the various layers of the bearing specimen at 510 MPa bearing stress and $4.0 \%$ bearing strain, with insert showing bearing plane SEM micrograph at similar load level

Figure 11: Damage distribution in the various layers of the bearing specimen at 530 MPa bearing stress and $8.0 \%$ bearing strain 
Table 1: Interface material properties (Ref: [24, 25])

\begin{tabular}{cccc}
\hline$K_{P}$ & $G_{z C}=G_{s h C}$ & $S_{z z}$ & $S_{x z}=S_{y z}=S_{s h}$ \\
$\left(\mathrm{~N} / \mathrm{mm}^{3}\right)$ & $(\mathrm{N} / \mathrm{mm})$ & $\left(\mathrm{N} / \mathrm{mm}^{2}\right)$ & $\left(\mathrm{N} / \mathrm{mm}^{2}\right)$ \\
\hline 50,000 & 1.1 & 50 & 50 \\
\hline
\end{tabular}

Table 2: Standard material properties for the composite layers (Ref: [16])

\begin{tabular}{ccccccccc}
\hline $\begin{array}{c}E_{11} \\
(\mathrm{GPa})\end{array}$ & $\begin{array}{c}E_{22} \\
(\mathrm{GPa})\end{array}$ & $\begin{array}{c}E_{33} \\
(\mathrm{GPa})\end{array}$ & $\begin{array}{c}G_{12} \\
(\mathrm{GPa})\end{array}$ & $\begin{array}{c}G_{13} \\
(\mathrm{GPa})\end{array}$ & $\begin{array}{c}G_{23} \\
(\mathrm{GPa})\end{array}$ & $\begin{array}{c}v_{12} \\
(-)\end{array}$ & $\begin{array}{c}v_{13} \\
(-)\end{array}$ & $\begin{array}{c}v_{23} \\
(-)\end{array}$ \\
\hline 49.57 & 12.15 & 12.15 & 6.09 & 6.09 & 4.05 & 0.28 & 0.28 & 0.28 \\
\hline
\end{tabular}

Table 3: Material data for composite damage model (Ref: [5, 16])

\begin{tabular}{cccccccccc}
\hline$\varepsilon_{11}^{i}$ & $\varepsilon_{11}^{u}$ & $\varepsilon_{11 C}^{i}$ & $\varepsilon_{11 C}^{u}$ & $S_{22}^{C}$ & $S_{12}$ & $S_{23}$ & $\mathrm{~b}$ & $d_{1}^{u}$ & $d_{\max }$ \\
$(\%)$ & $(\%)$ & $(\%)$ & $(\%)$ & $(\mathrm{MPa})$ & $(\mathrm{MPa})$ & $(\mathrm{MPa})$ & $(-)$ & $(-)$ & $(-)$ \\
\hline 3.75 & 4.0 & 2.19 & 4.0 & 150 & 50 & 50 & 1.7 & 0.99 & 0.95 \\
\hline
\end{tabular}




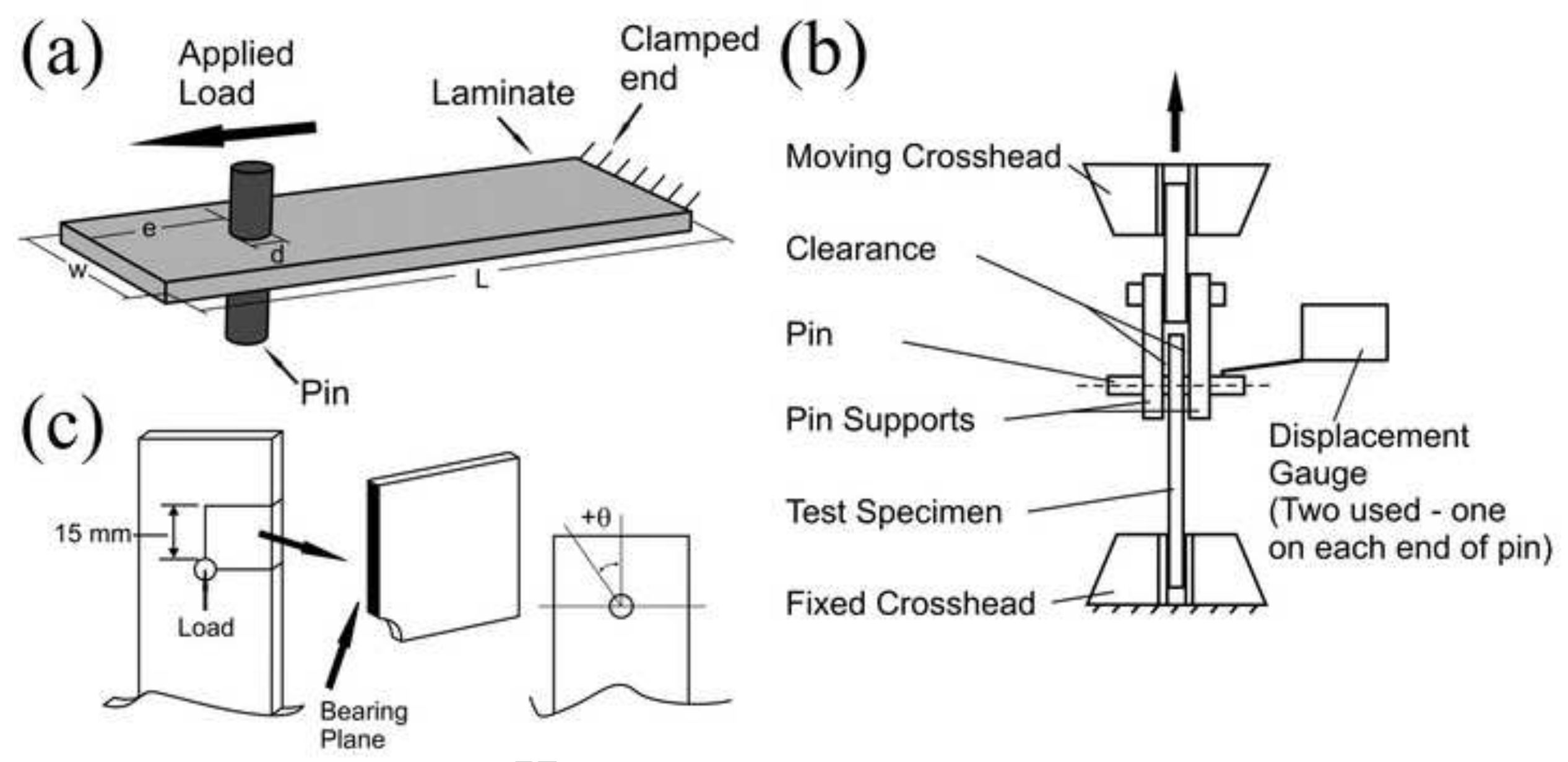


(a)
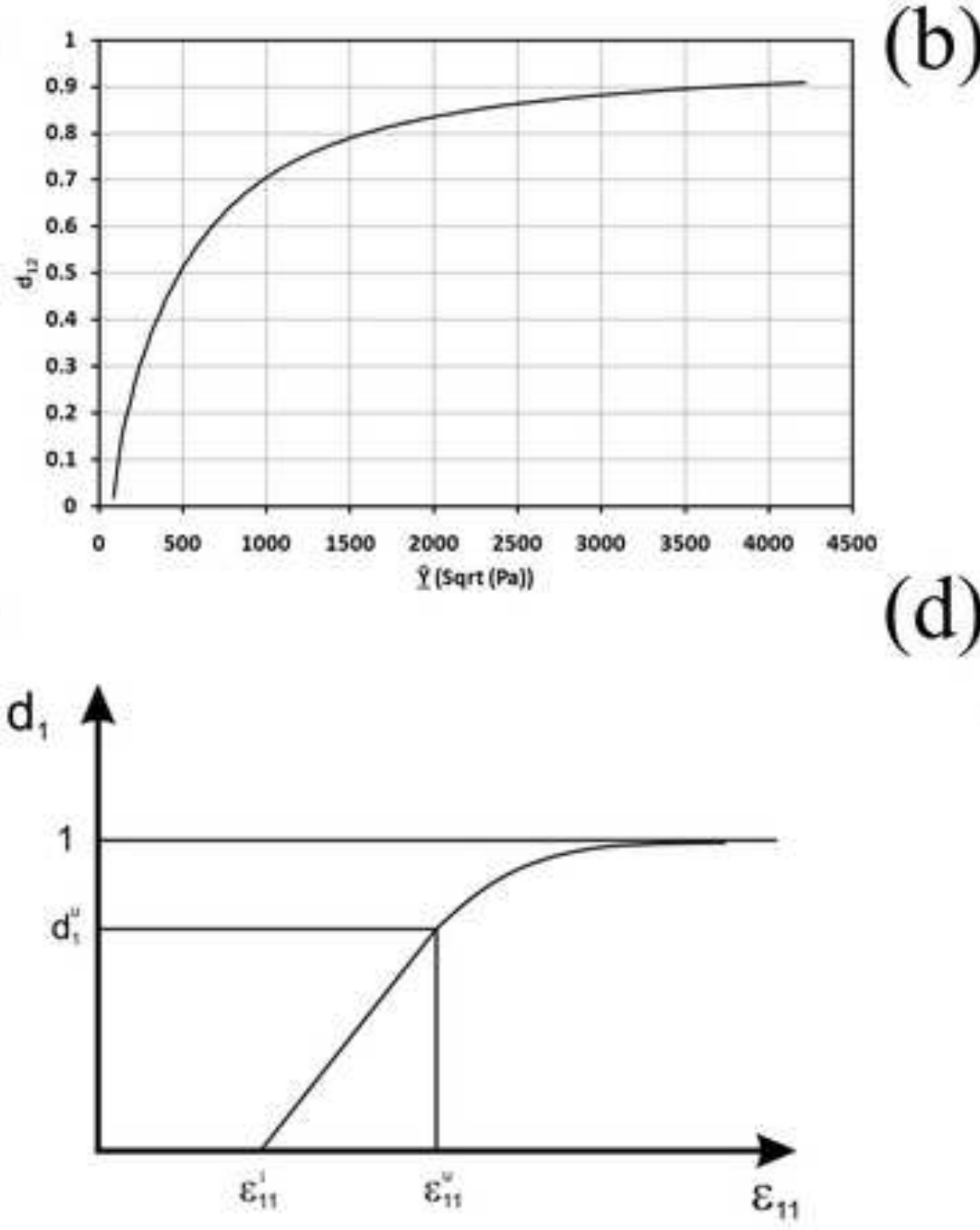

(b)

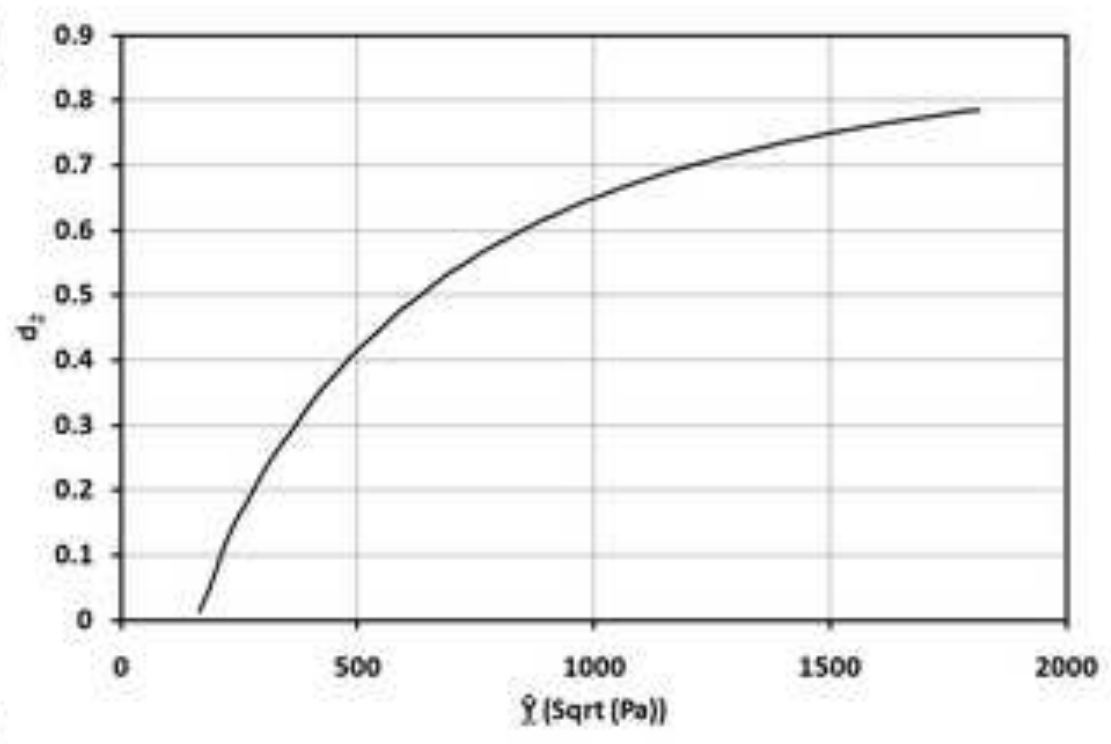

(c)

(d)

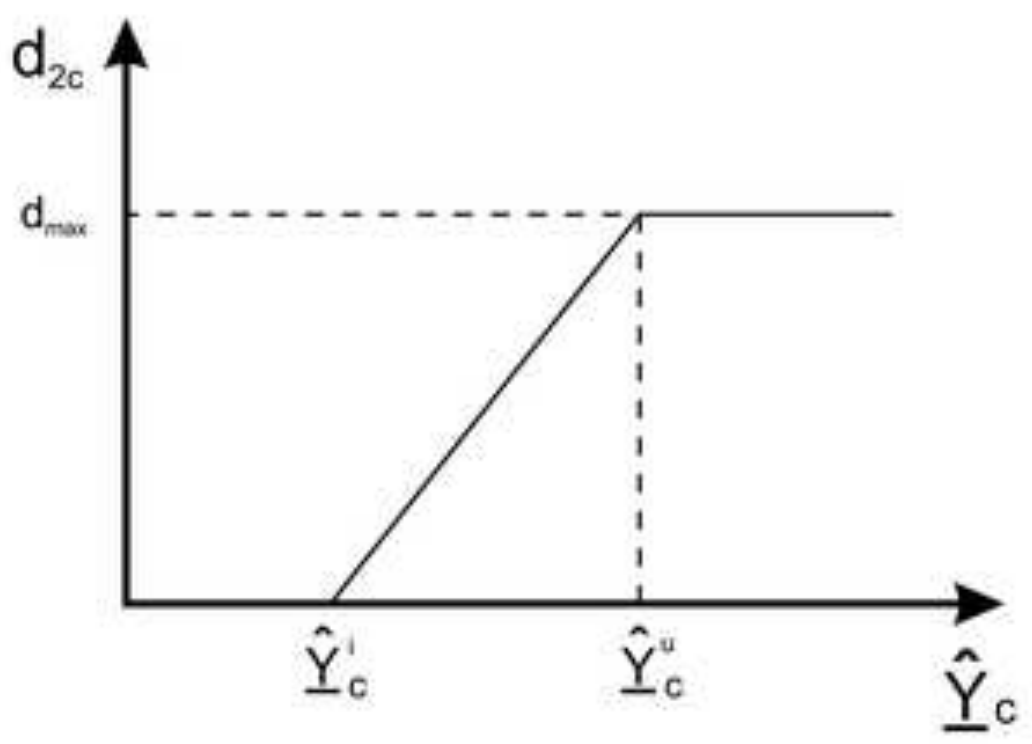




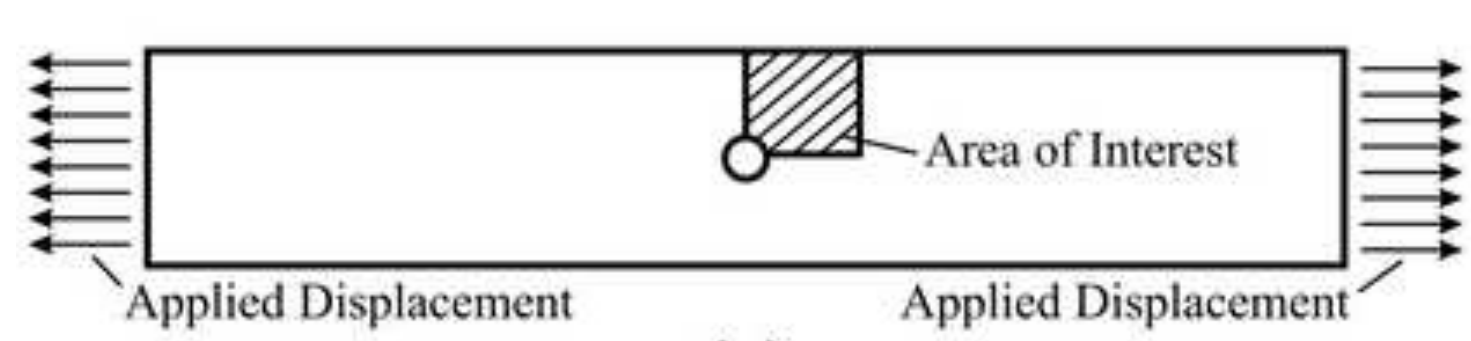

Mesh $1=5760 \mathrm{DOF}^{*}$ Mesh $2=16320$ DOF Mesh $3=39168$ DOF Mesh $4=114336$ DOF

(a) * DOF $=$ Degrees of freedom

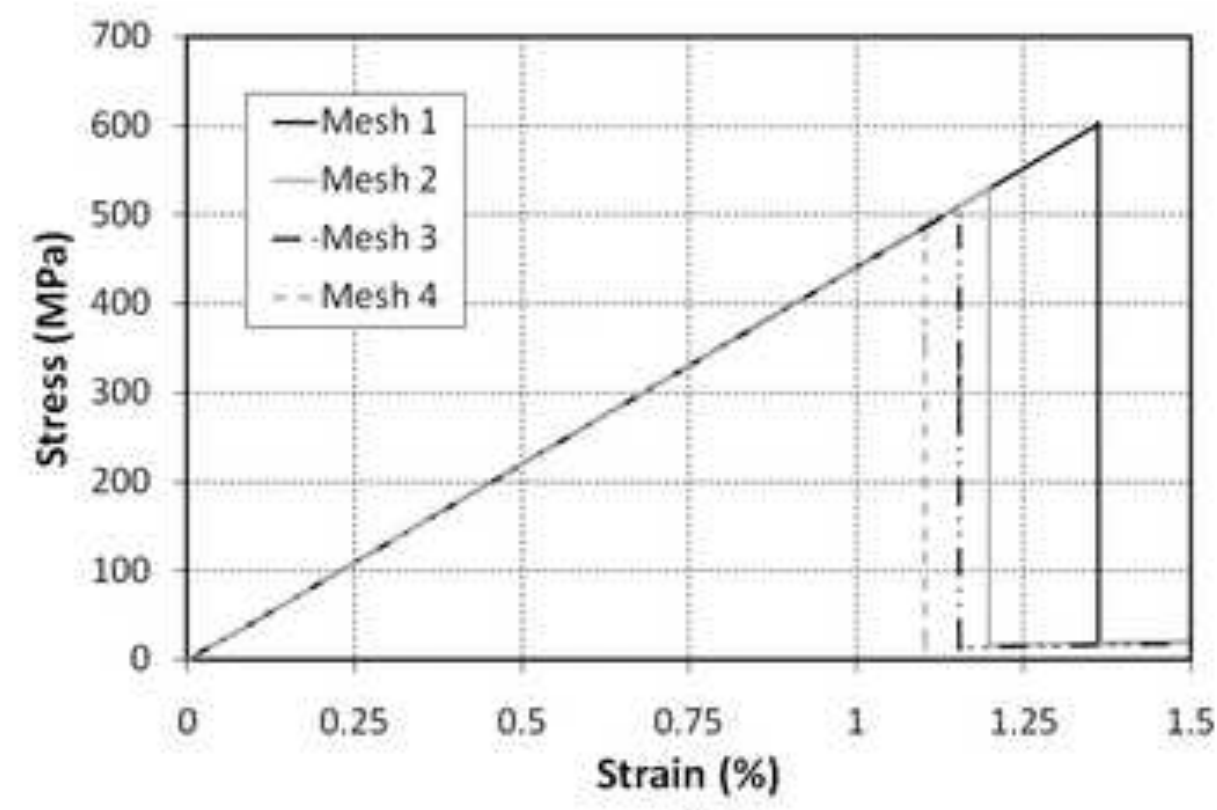

(b)

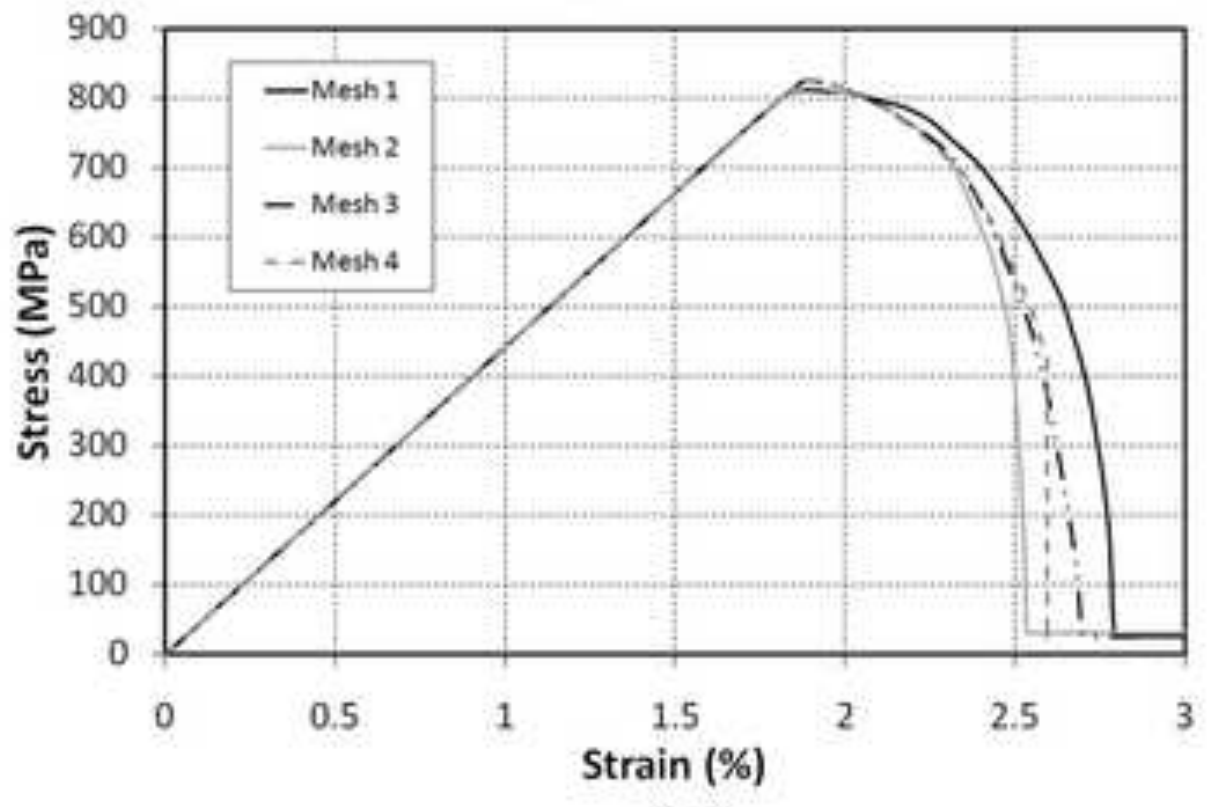

(c) 

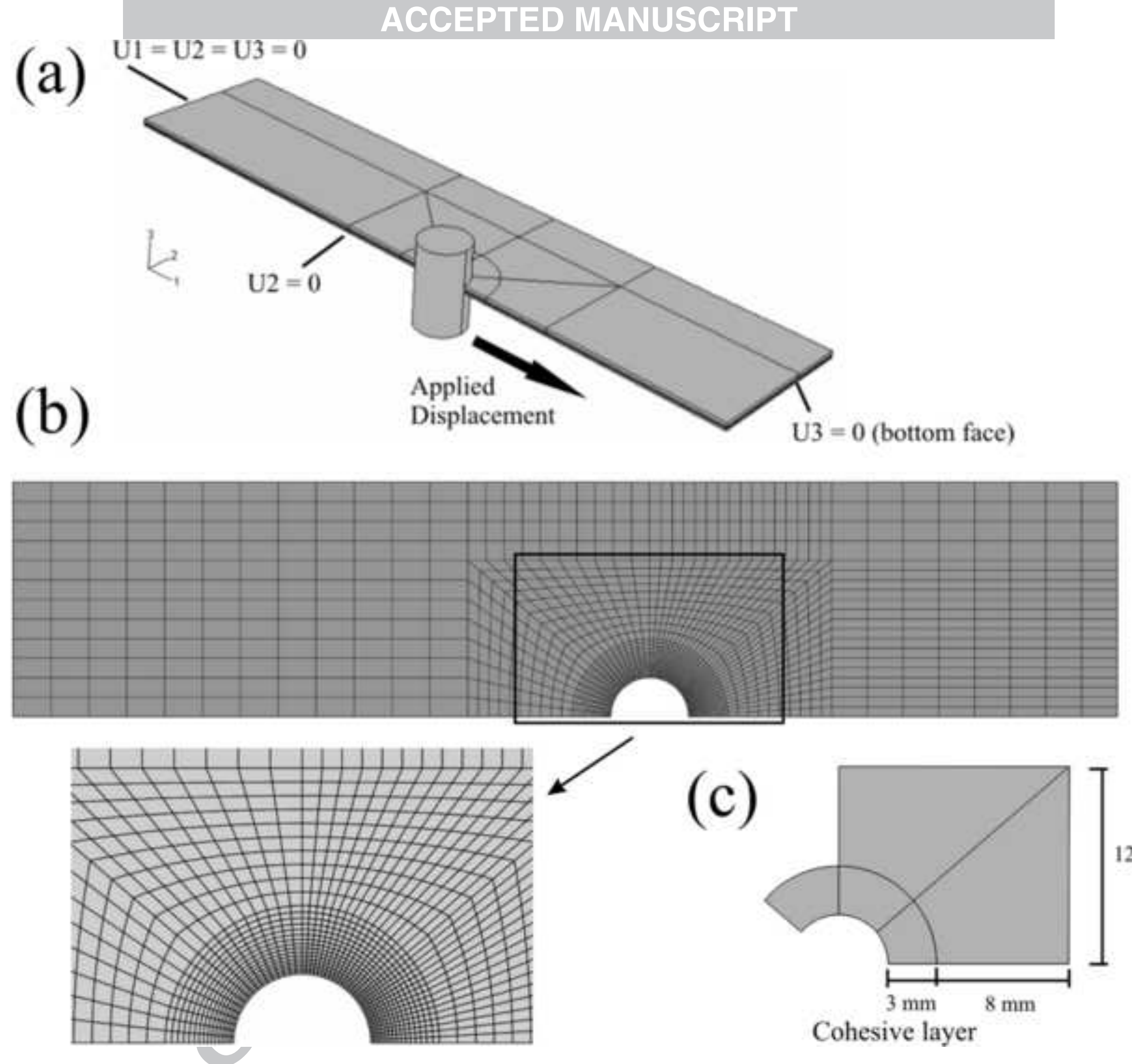

(c)

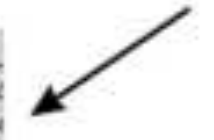

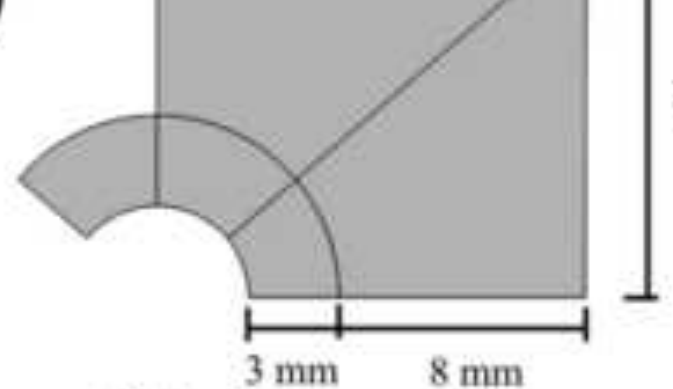

Cohesive laỹer 

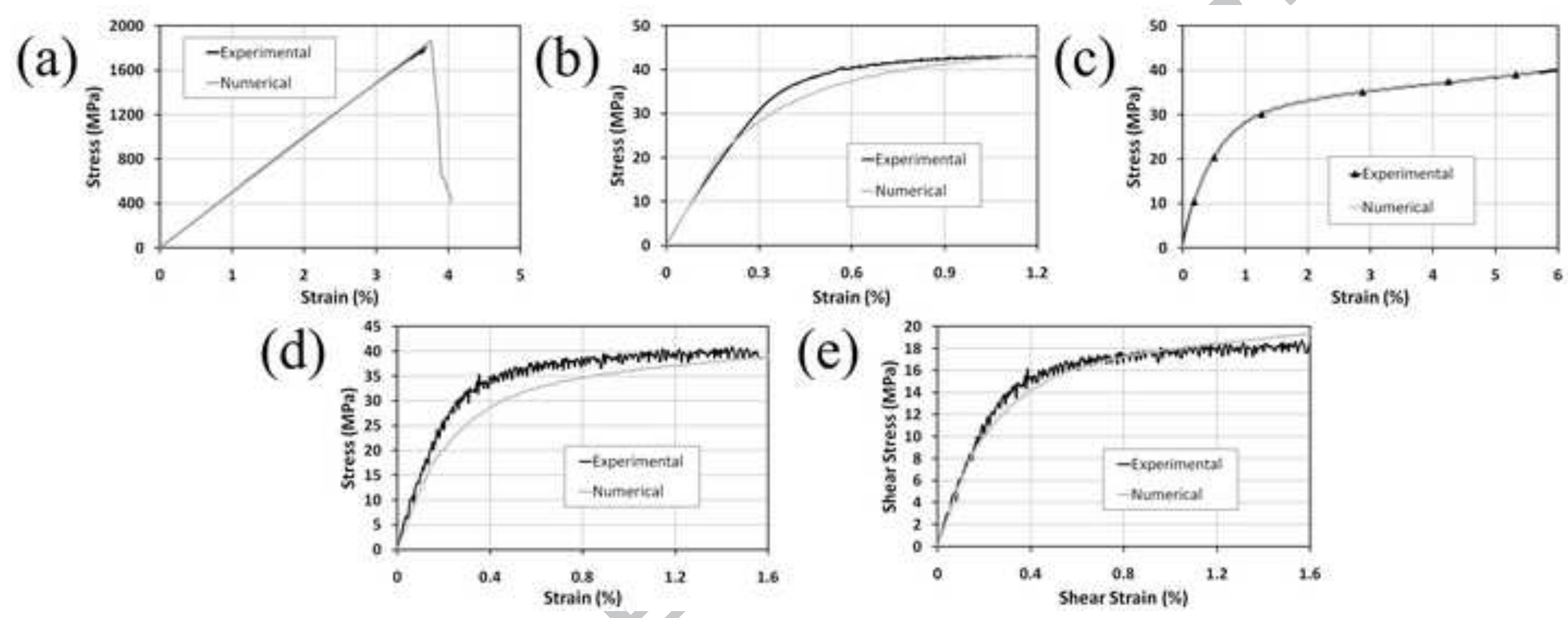


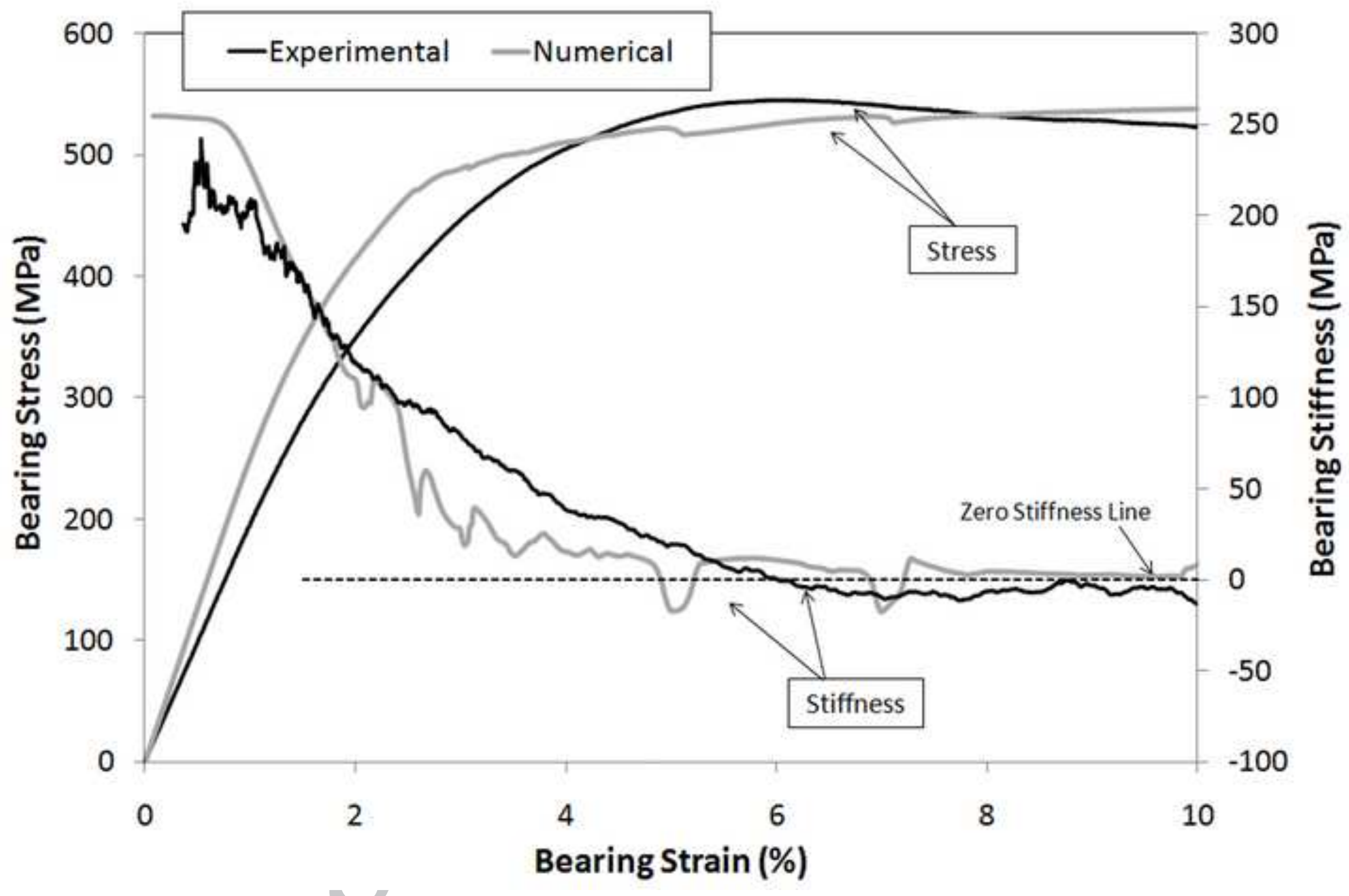




\section{Outer Aluminium}

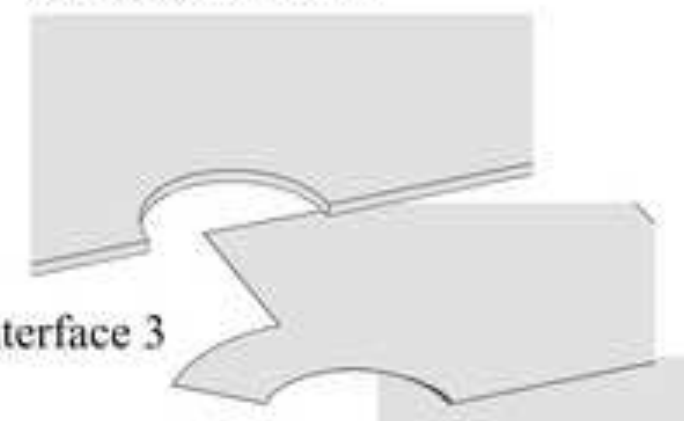

Interface 3

\section{Interface 2}
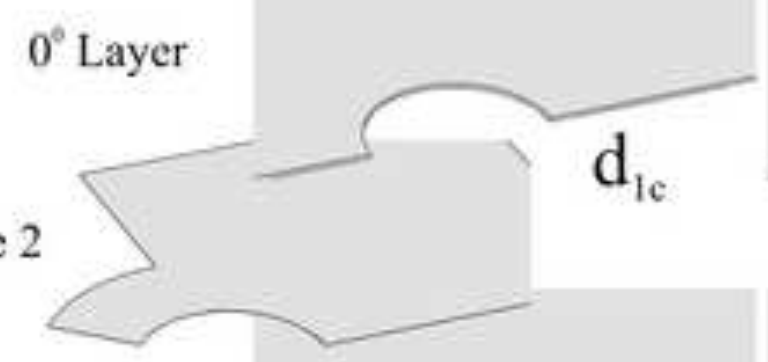

$90^{\circ}$ Layer

Interface 1

Inner Aluminium
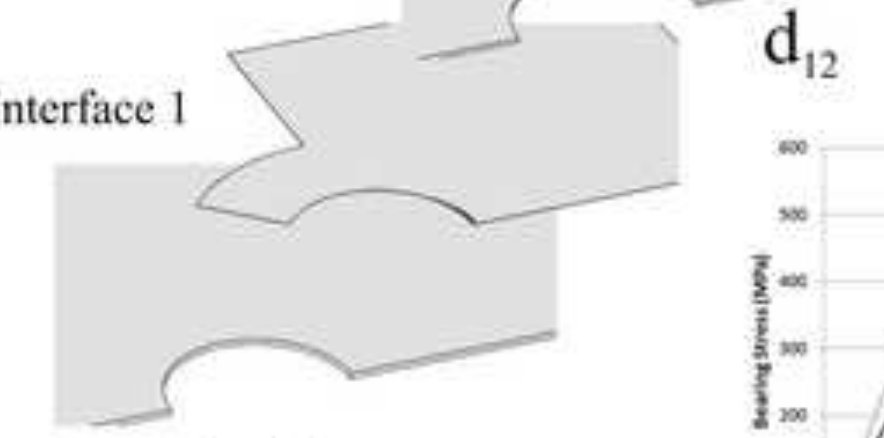

\section{Damage Legend}

$\begin{array}{lllllll}1.0 & 0.8 & 0.6 & 0.4 & 0.2 & 0.0\end{array}$

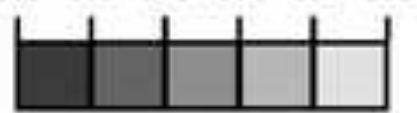

Plasticity Legend

(Max. Plastic Strain: 0.0037)

$\begin{array}{llllllll}5.0 & 4.0 & 3.0 & 2.0 & 1.0 & 0.0 & \left(\mathrm{x} 10^{\circ}\right)\end{array}$

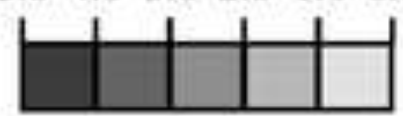

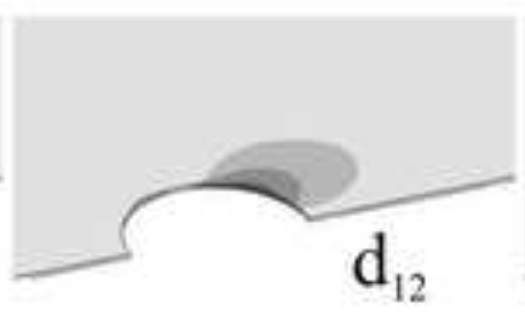
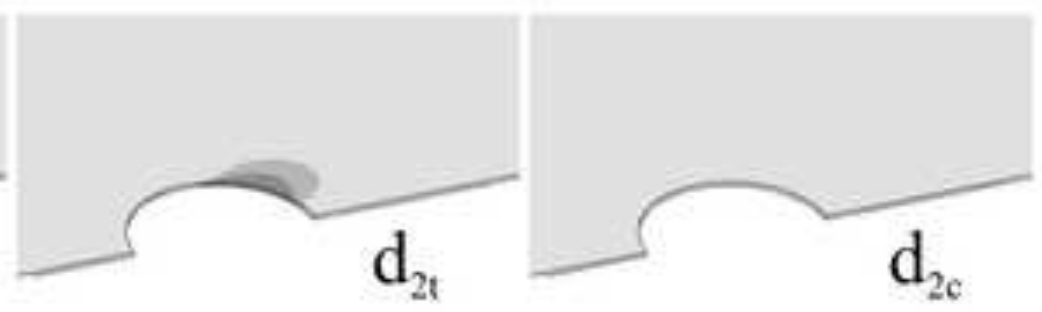

$\mathrm{d}_{2 \mathrm{c}}$
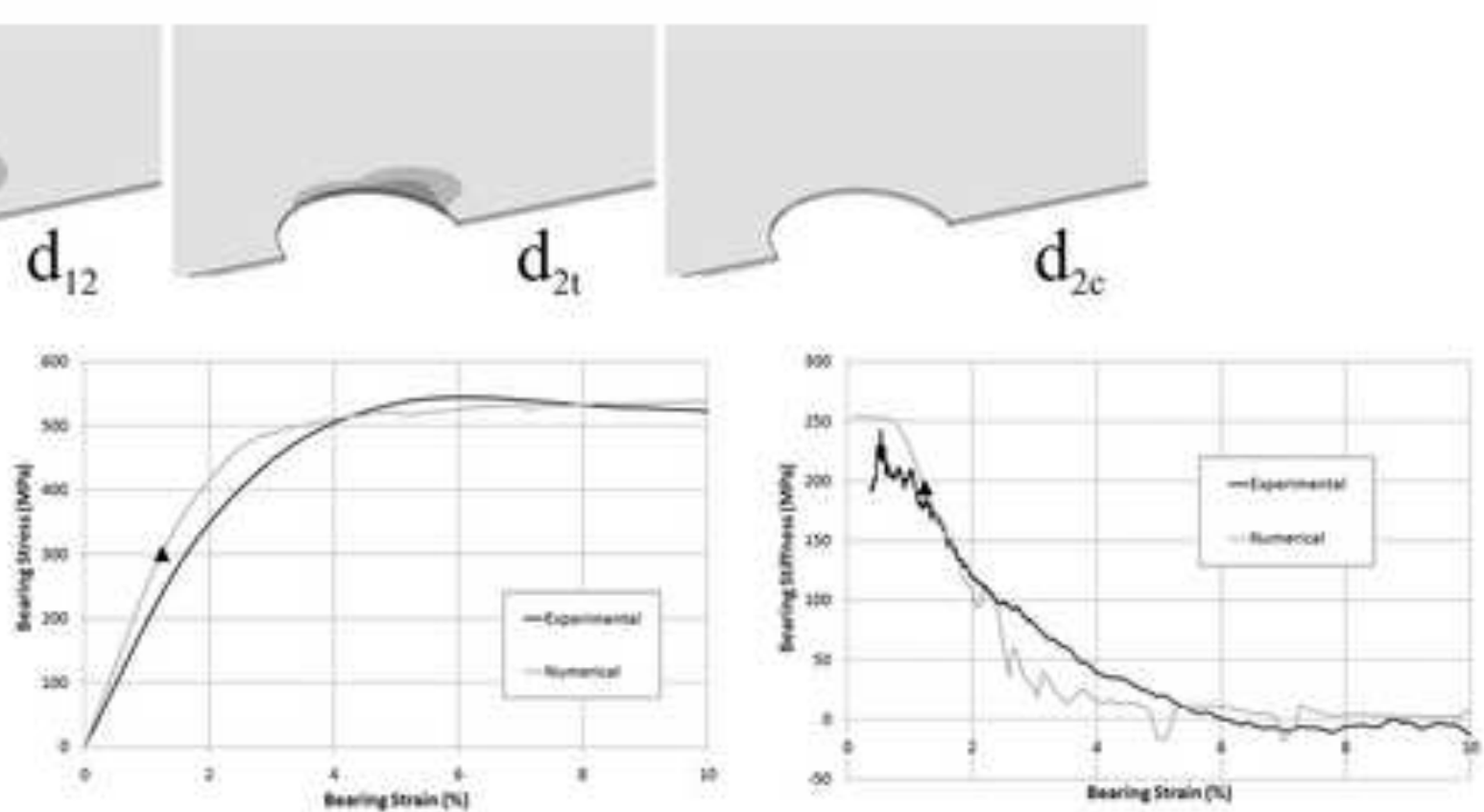


\section{Outer Aluminium}

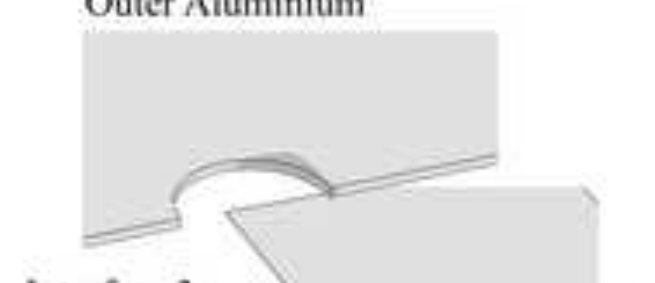

ACCEPTED MANUSCRIPT

\section{Damage Legend}

$\begin{array}{llllll}1.0 & 0.8 & 0.6 & 0.4 & 0.2 & 0.0\end{array}$

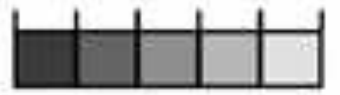

Plasticity Legend

(Max. Plastic Strain: 0.02)

$\begin{array}{lllllll}5.0 & 4.0 & 3.0 & 2.0 & 1.0 & 0.0 & \left(\times 10^{7}\right)\end{array}$

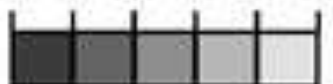

Interface 3
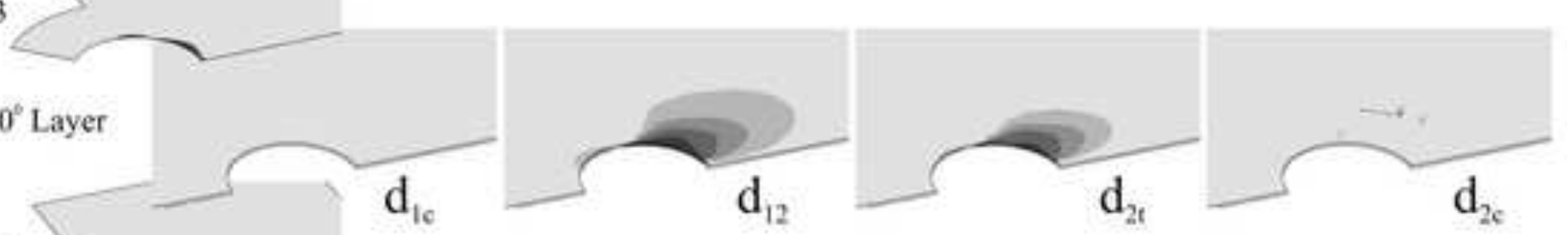

Interface 2

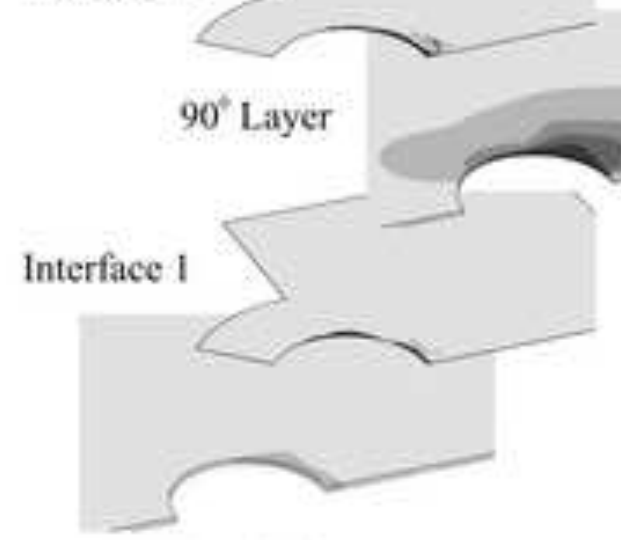

Inner Aluminium
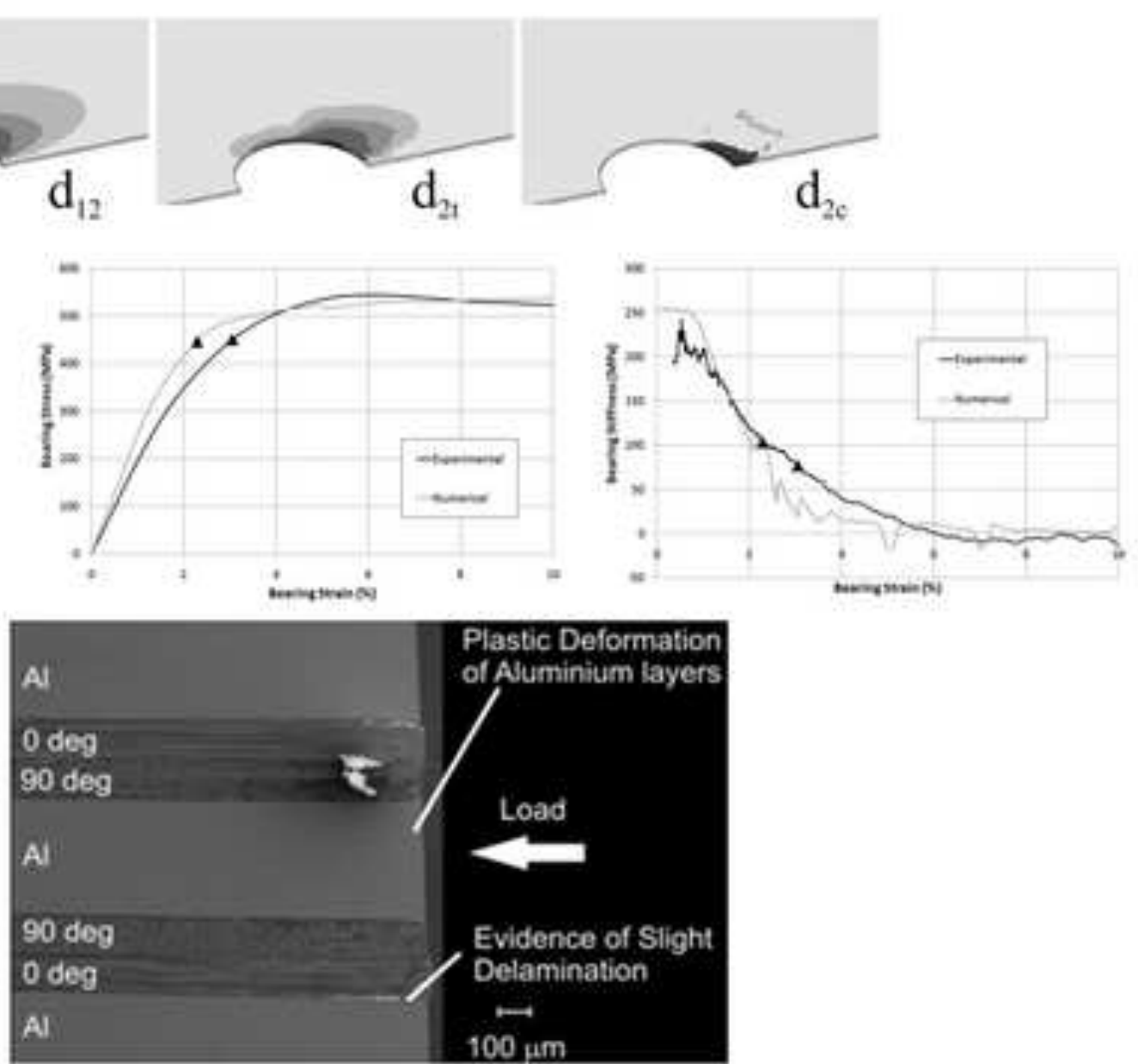

$100 \mu \mathrm{m}$ 


\section{Outer Aluminium}

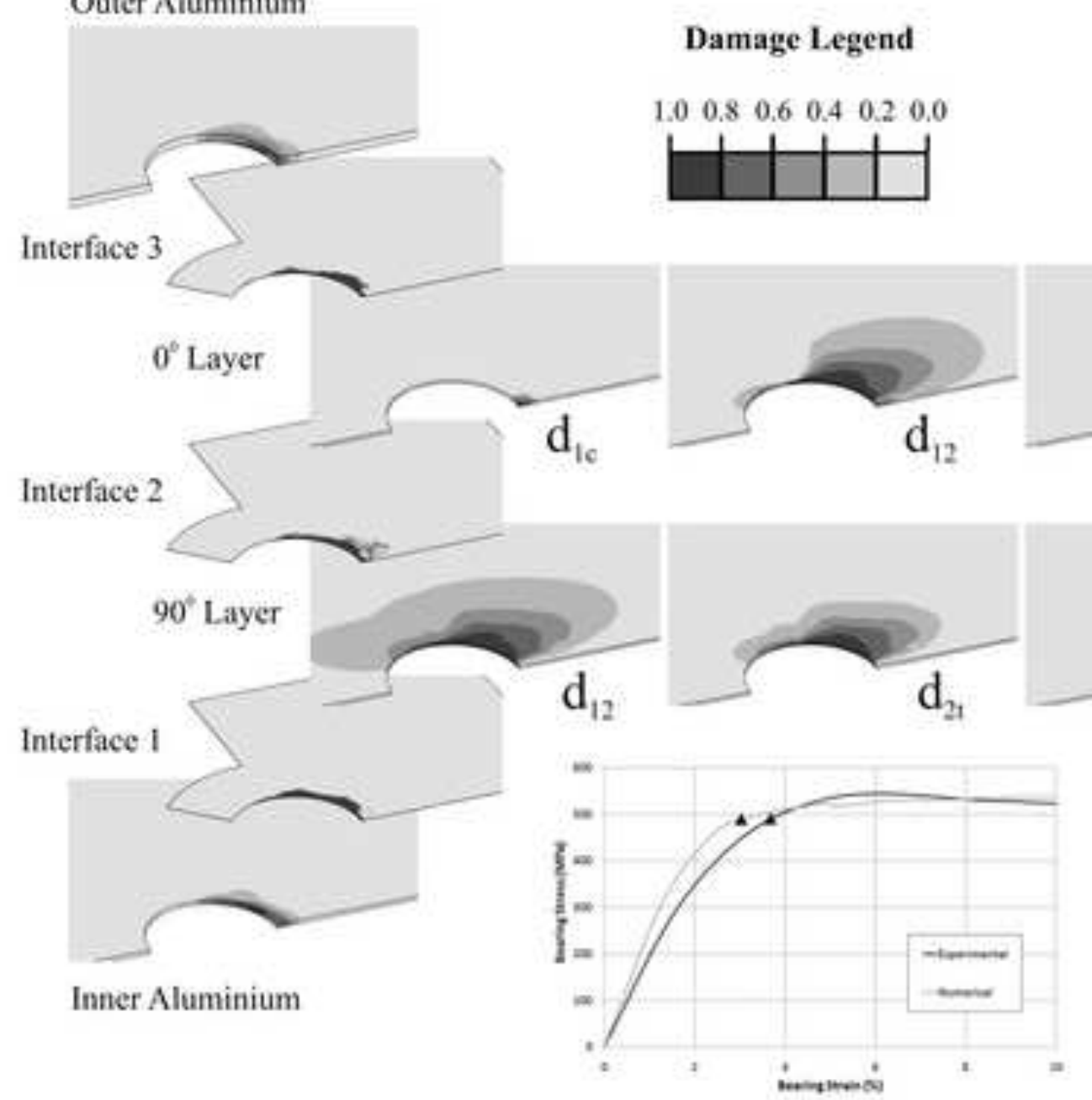

Plasticity Legend

(Max. Plastic Strain: 0.054)

$\begin{array}{llllllll}5.0 & 4.0 & 3,0 & 2.0 & 1.0 & 0.0 & \left(\times 10^{5}\right)\end{array}$

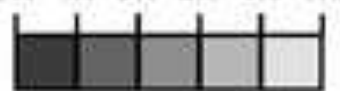

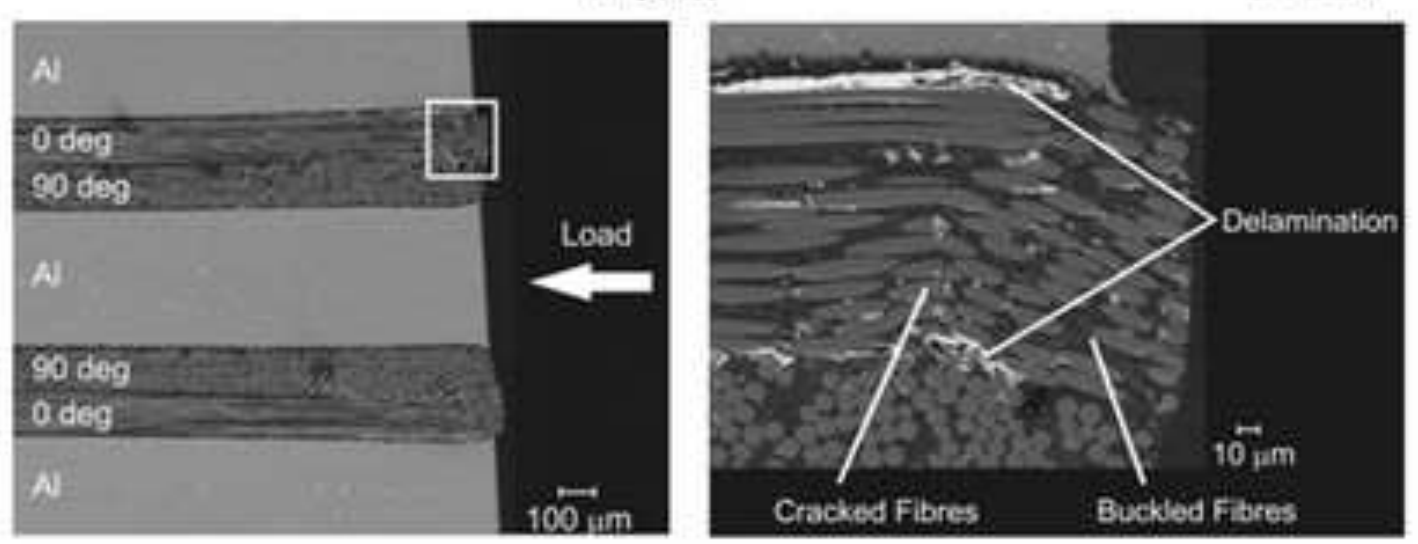

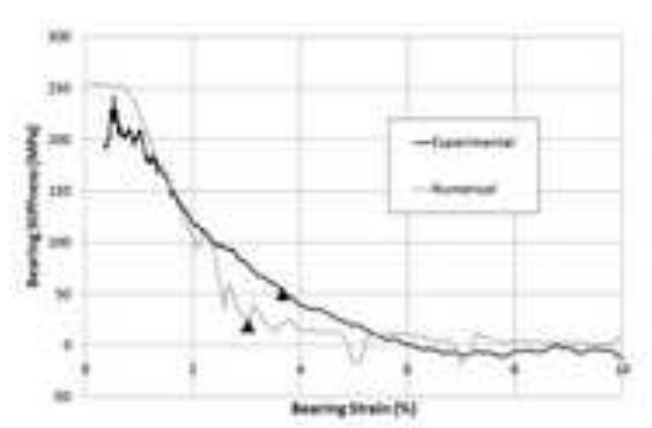




\section{Outer Aluminium}

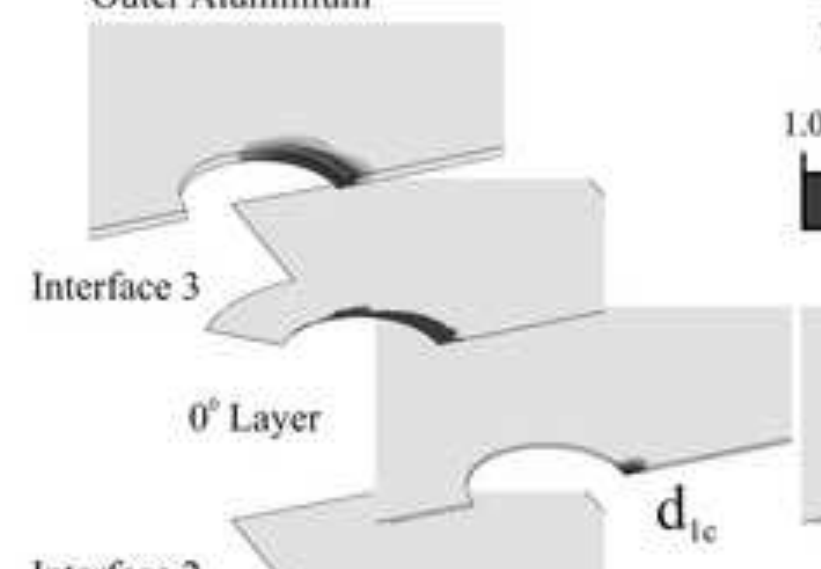

Interface 2

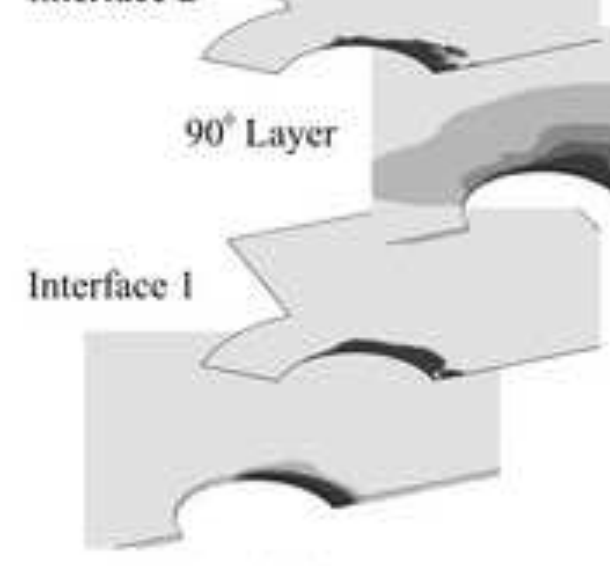

Inner Aluminium

\section{ACCEPTED MANUSCRIPT}

\section{Damage Legend}

$\begin{array}{llllllll}1.0 & 0.8 & 0.6 & 0.4 & 0.2 & 0.0\end{array}$

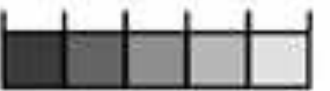

Plasticity Legend

(Max. Plastic Strain: 0.14)

$\begin{array}{lllllll}5.0 & 4.0 & 3.0 & 2.0 & 1.0 & 0.0 & \left(\times 10^{7}\right)\end{array}$

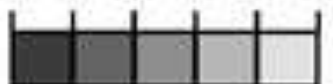

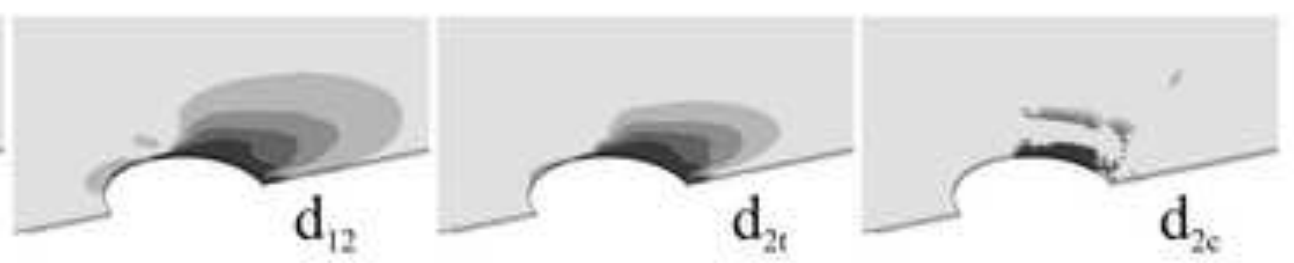

$d_{2 c}$

Iner Aluminium
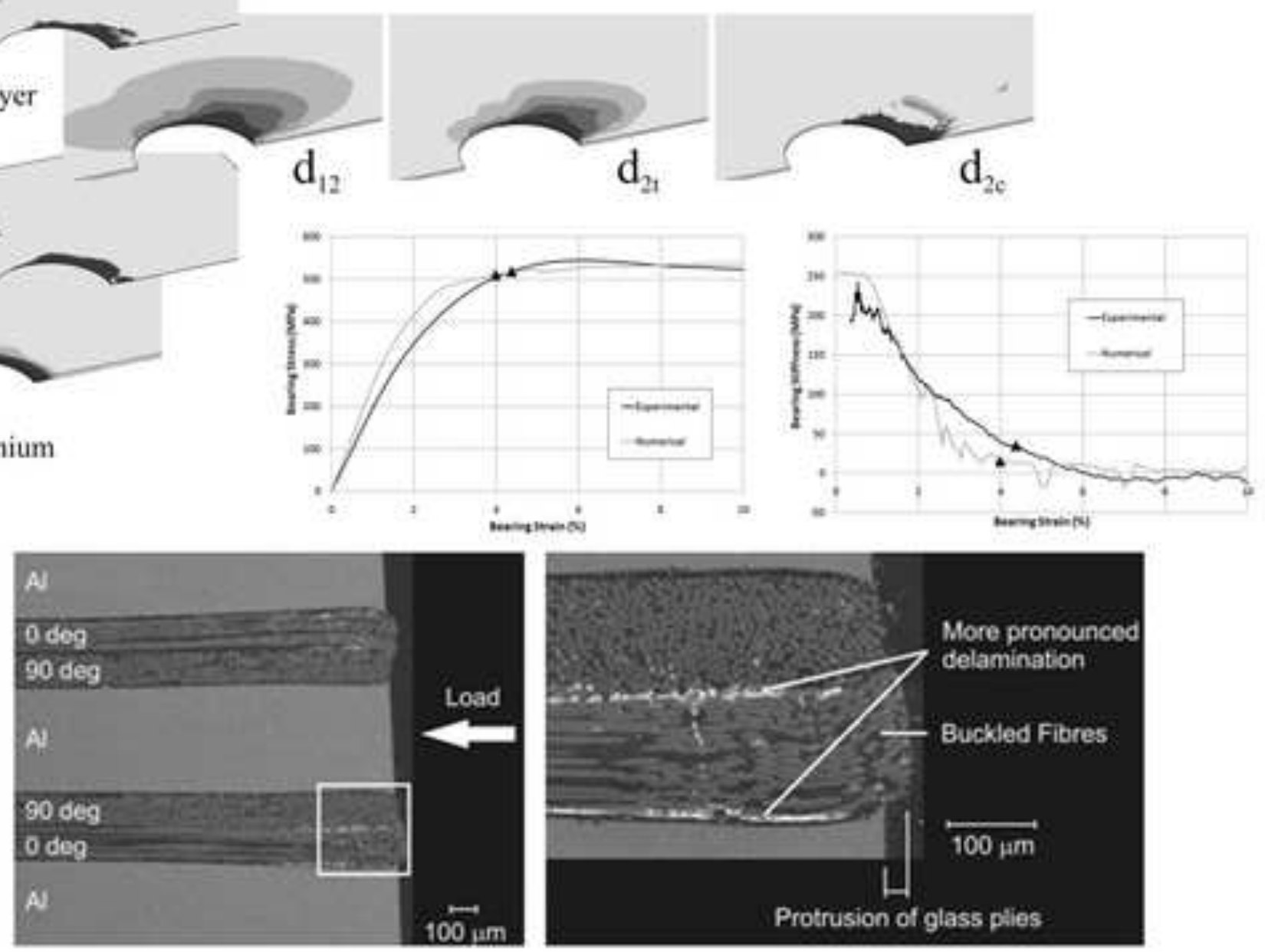

Protrusion of glass plies 


\section{Outer Aluminium}

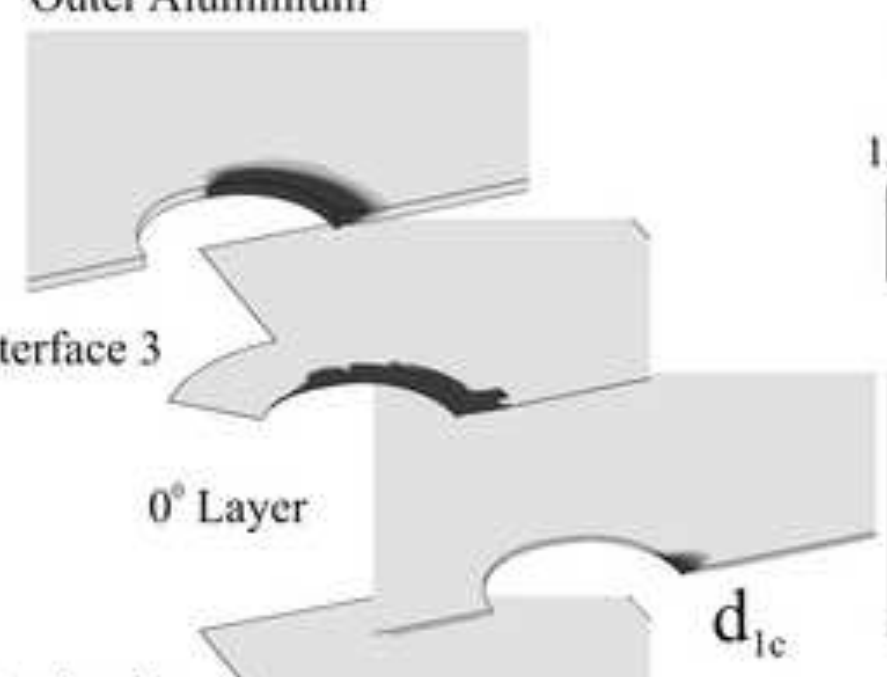

Interface 2

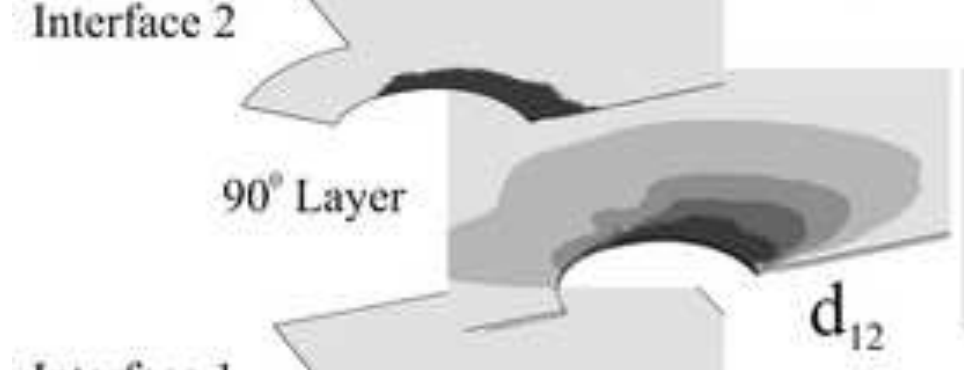

Interface 1

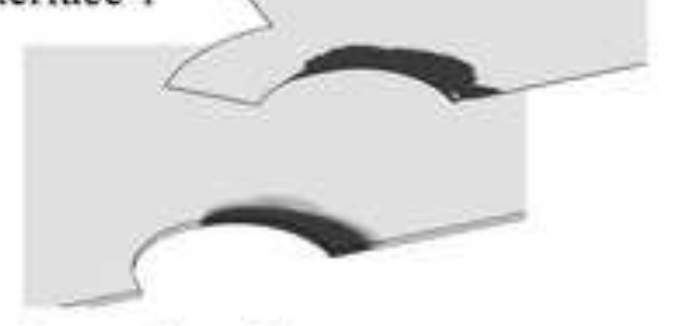

Inner Aluminium

\section{Damage Legend}

$\begin{array}{lllllll}1.0 & 0.8 & 0.6 & 0.4 & 0.2 & 0.0\end{array}$

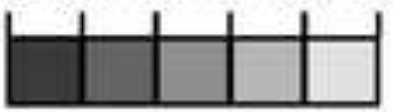

Plasticity Legend

(Max. Plastic Strain: 1.12)

$\begin{array}{lllllll}5.0 & 4.0 & 3.0 & 2.0 & 1.0 & 0.0 & \left(\mathrm{x} 10^{2}\right)\end{array}$

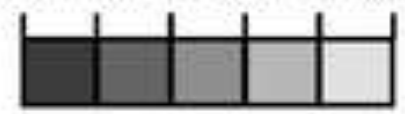

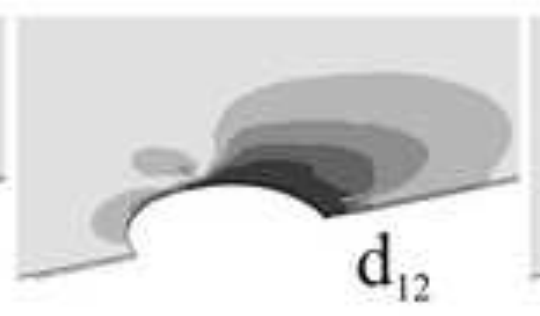
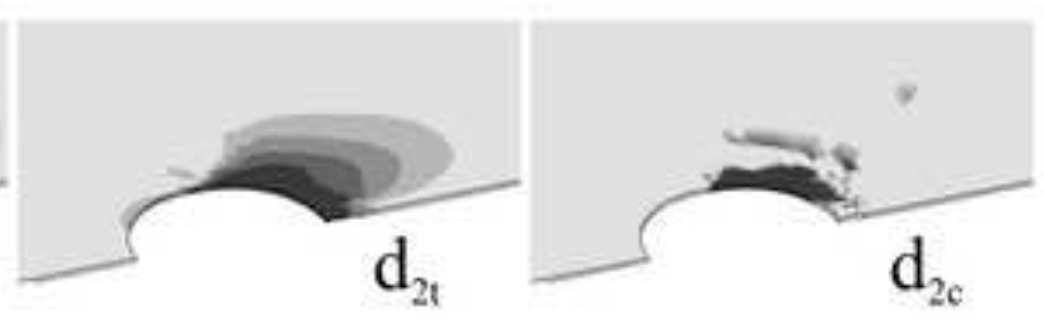

$\mathrm{d}_{2 \mathrm{c}}$
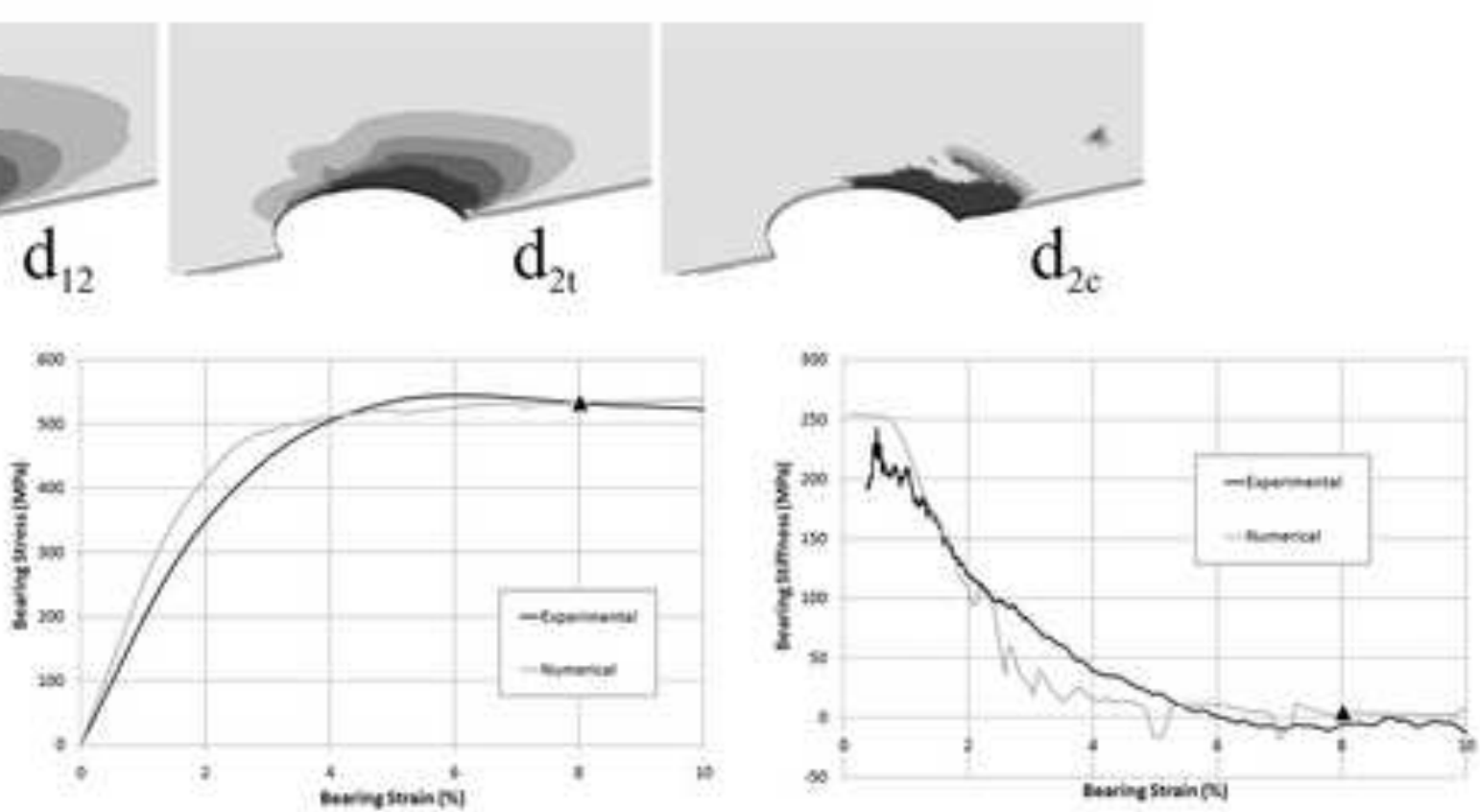